\title{
A RAP1-interacting protein involved in transcriptional silencing and telomere length regulation
}

\author{
Christopher F.J. Hardy, ${ }^{1}$ Lori Sussel, and David Shore ${ }^{2}$ \\ Department of Microbiology, College of Physicians and Surgeons of Columbia University, New York, New York 10032 USA
}

The yeast RAP1 protein is a sequence-specific DNA-binding protein that functions as both a repressor and an activator of transcription. RAP1 is also involved in the regulation of telomere structure, where its binding sites are found within the terminal poly $\left(\mathrm{C}_{1-3} \mathrm{~A}\right)$ sequences. Previous studies have indicated that the regulatory function of RAP1 is determined by the context of its binding site and, presumably, its interactions with other factors. Using the two-hybrid system, a genetic screen for the identification of protein-protein interactions, we have isolated a gene encoding a RAP1-interacting factor (RIF1). Strains carrying gene disruptions of RIF1 grow normally but are defective in transcriptional silencing and telomere length regulation, two phenotypes strikingly similar to those of silencing-defective $\operatorname{rap} 1^{s}$ mutants. Furthermore, hybrid proteins containing rap $1^{s}$ missense mutations are defective in an interaction with RIF1 in the two-hybrid system. Taken together, these data support the idea that the rap $1^{s}$ phenotypes are attributable to a failure to recruit RIF1 to silencers and telomeres and suggest that RIF1 is a cofactor or mediator for RAP1 in the establishment of a repressed chromatin state at these loci. By use of the two-hybrid system, we have isolated a mutation in RIF1 that partially restores the interaction with rap $^{\text {s }}$ mutant proteins.

[Key Words: Transcriptional silencing; telomere structure; Saccharomyces cerevisiae; RAP1; protein-protein interactions; two-hybrid system]

Received January 13, 1992; revised version accepted March 4, 1992.

Repressor/activator protein 1 (RAPl) is an essential regulatory protein in yeast whose DNA-binding sites are found at three types of chromosomal elcments: promoters, silencers, and telomeres. Analyses of rap1 mutants have revealed that the protein acts at all three types of loci. Temperature-sensitive lethal mutations in RAP1 $\left(\right.$ rap $\left.1^{t s}\right)$ are defective in transcriptional activation, an apparently essential function of RAPl (Giesman et al. 1991; Kurtz and Shore 1991). Although one rap $1^{t s}$ strain is also partially defective in silencing (Kurtz and Shore 1991), the repression function of RAP1 can be genetically separated from essential activation functions, as demonstrated by the isolation of several viable mutants $\left(\right.$ rap $\left.1^{s}\right)$ that are specifically defective in transcriptional silencing (Sussel and Shore 1991). Both types of rap1 mutants $\left(\right.$ rap $1^{\text {ts }}$ and rap $\left.1^{s}\right)$ also display changes in the poly $\left(\mathrm{C}_{1-3} \mathrm{~A}\right)$ sequences at telomeres, which contain RAP1-binding sites approximately every 40 bp (Longtine et al. 1989). When grown at semipermissive temperatures, where RAP1 function is limiting, rap ${ }^{1 s}$ mutants undergo a progressive loss of poly $\left(\mathrm{C}_{1-3} \mathrm{~A}\right)$ sequences (Conrad et al. 1990; Lustig et al. 1990|. Conversely, silencing-defective

\footnotetext{
${ }^{1}$ Present address: Cold Spring Harbor Laboratory, Cold Spring Harbor, New York 11724 USA.

${ }^{2}$ Corresponding author.
}

rap1 $1^{s}$ mutants have longer poly $\left(\mathrm{C}_{1-3} \mathrm{~A}\right)$ tracts, the lengthening effect being proportional to the strength of the silencing defect (Sussel and Shore 1991).

Several observations suggest that the opposite regulatory functions of RAPl are not intrinsic to its binding sites but, instead, result from interactions with different factors at promoters and silencers. For example, the particular DNA sequence of a RAPl-binding site does not determine its regulatory function: Promoter-derived binding sites function in place of a normal silencer site and vice versa (Brand et al. 1987; Shore and Nasmyth 1987; Buchman et al. 1988b). Furthermore, silencers and promoters containing RAP1-binding sites typically appear to be complex regulatory sites in which at least one other regulatory element is required for either proper repression or activation (Rotenberg and Woolford 1986; Brand et al. 1987; Kimmerly et al. 1988; Stanway et al. 1989|. Several candidates exist for RAPl-interacting factors at silencers (e.g., SIR1-SIR4 and ABF1) (Rine and Herskowitz 1987; Shore et al. 1987; Buchman et al. 1988a; Diffley and Stillman 1988) and at promoters (e.g., GCR1 or GAL11/SPT13) (Fassler and Winston 1989; Nishizawa 1990; Santangelo and Tornow 1990). No biochemical or genetic data, however, directly indicate that any of these proteins physically interacts with RAP1.

Recently, we have shown that high-level expression of 
the carboxyl terminus of RAP1 fused to the GAL4 DNAbinding domain $\left(\mathrm{G}_{\mathrm{BD}}\right)$ causes a dominant-negative effect on silencing, leading to the derepression of normally silent genes at the HMR locus (Hardy et al. 1992). Overexpression of the carboxyl terminus of RAPl also results in telomere elongation (Conrad et al. 1990; Hardy 1991), another phenotype associated with $\operatorname{rap} 1^{s}$ mutants. Derepression by $\mathrm{G}_{\mathrm{BD}} / \mathrm{RAPl}$ hybrids occurs only when they are expressed from a strong promoter on multicopy plasmids and not when expressed from the RAP1 promoter in single copy. Furthermore, this dominant-negative effect is not dependent on a DNA-binding site to target the hybrids to the silencer. We reasoned, therefore, that derepression results from the titration of limiting silencer factors. The part of RAPl responsible for this dominantnegative effect on silencing was mapped to a region from amino acid 667 to the carboxyl terminus /amino acid 8271 , the same region of the protein to which the silencing-defective rap $1^{\text {s }}$ mutants map. Our results indicated that this putative titrated factor is probably neither RAP1 itself nor the other silencer binding factor ABFl (Hardy et al. 1992).

On the basis of these results, we have used a novel genetic system (Fields and Song 1989; Chien et al. 1991) to identify a protein that interacts with the RAPl carboxyl terminus. We report the cloning and characterization of a gene encoding such a protein, designated RIF1 (for RAP1-interacting factor 1). Strains carrying disruptions of the RIF1 gene are defective in silencing and have elongated poly $\left(\mathrm{C}_{1-3} \mathrm{~A}\right)$ tracts at telomeres, both phenotypes characteristic of rap $1^{S}$ mutants. By use of the twohybrid system, we have shown that the region of RAPI required for the silencer derepression effect (amino acids 667-827) is also necessary for the RAP1-RIF1 proteinprotein interaction. Furthermore, hybrids made with the different rap $1^{\mathrm{s}}$ mutants display a defect in interacting with RIF 1 that is proportional to the corresponding rap $1^{5}$ silencing defects. These results suggest that one function of RAPl, defective in the rap $1^{\mathrm{s}}$ mutants, is to direct the binding of RIFl to silencers and telomeres. Interestingly, two rap $1^{\text {s }}$ hybrids that appear to be completely unable to interact with RIFl in the two-hybrid system still lead to silencer derepression when overexpressed, suggesting that the RAP1 carboxyl terminus may also interact with other factors at silencers and telomeres not yet unidentified.

\section{Results}

Isolation of a RAP1-interacting protein by the two-hybrid system

Expression of $\mathrm{G}_{\mathrm{BD}} / \mathrm{RAP} 1$ hybrids from a strong promoter results in derepression of the silent $H M R$ locus, presumably as the result of protein-protein interactions that either sequester or titrate another factor important for silencing (Hardy et al. 1992). In an attempt to identify this putative RIF, we have used the two-hybrid system, a genetic method to identify protein-protein interactions (Fields and Song 1989; Chien et al. 1991). This method utilizes the separable domains of the transcriptional activator GAL4, its amino-terminal DNA-binding domain $\left(\mathrm{G}_{\mathrm{BD}}\right.$, amino acids 1-147), and its carboxy-terminal transcriptional activation domain $\left(\mathrm{G}_{\mathrm{AD}}\right.$, amino acids 768 881). Fields and co-workers showed that coexpression in yeast of two interacting proteins $(\mathrm{X}$ and $\mathrm{Y})$ as $\mathrm{G}_{\mathrm{BD}} / \mathrm{X}$ and $\mathrm{G}_{\mathrm{AD}} / \mathrm{Y}$ hybrids resulted in the activation of a GAL1lacZ reporter gene. Activation occurs presumably by a protein-protein interaction between the $\mathrm{X}$ and $\mathrm{Y}$ portions of the two hybrids that tethers the activation domain to the promoter. We have adapted the two-hybrid screen to isolate RAPl-interacting proteins by starting with a $G A L 1-$ lacZ reporter strain expressing the $\mathrm{G}_{\mathrm{BD}} /$ RAPl (653-827) hybrid. This strain was then transformed with a library of plasmids in which yeast genomic fragments (produced by partial digestion with the enzyme Sau3A/ were fused to sequences encoding the SV40 T antigen nuclear localization signal followed by the $\mathrm{G}_{\mathrm{AD}}$ (a generous gift of P. Bartel and S. Fields). Approximately 120,000 transformants were replica plated onto X-gal plates, and 11 blue colonies were identified and purified (for details, see Materials and methods). Potential activation domain hybrids encoded on LEU2-containing plasmids were isolated from these cells and transformed back into two different reporter strains, one with and one without the $\mathrm{G}_{\mathrm{BD}} / \operatorname{RAP} 1(653-827)$ hybrid plasmid. Of the 11 plasmids, 10 activated in both reporter strains and, by restriction mapping, appeared to contain all or portions of the GAL4 gene.

A single $G_{A D}$ plasmid was found to confer $G_{B D} /$ RAP1(653-827)-dependent activation of the reporter gene (Fig. 1). Activation requires the RAPl portion of the $\mathrm{G}_{\mathrm{BD}} / \mathrm{RAP} 1$ hybrid; no activation is observed when the plasmid is transformed into a strain expressing the $G_{B D}$ alone. The hybrid is therefore not targeted to the reporter gene through a direct $\mathrm{G}_{\mathrm{BD}}$ interaction but, instead, encodes a polypeptide that interacts with RAPI $(653-827)$, which will be referred to hereafter as RIF1. Subsequent analysis (see below) indicated that the plasmid contained a carboxy-terminal region of the RIF1 gene fused inframe to $G_{A D}$-coding sequences. To demonstrate that the activation effect required the production of a $\mathrm{G}_{\mathrm{AD}}$ / RIF1 fusion protein, the following experiments were done. First, a frameshift mutation was created between $\mathrm{G}_{\mathrm{AD}}$ and RIFl sequences (at a BamHI site) to truncate the fusion protein just beyond the $G_{A D}$ sequences. This frameshift mutation in the $\mathrm{G}_{\mathrm{AD}}$ /RIF1 hybrid abolishes activation, demonstrating that the RIFl portion of the hybrid is required for activation of the GAL1-lacZ reporter gene (Fig. 1). However, two downstream frameshift mutations, at a unique NcoI site and a distal BamHI site, had no effect on activation by the $\mathrm{G}_{\mathrm{AD}} / \mathrm{RIF} 1$ plasmid, indicating that any coding sequences beyond these two sites are not necessary for the interaction. To determine the $3^{\prime}$ end point of RIF1 sequences required for activation, two other mutations in the insert DNA were constructed. Deletion of sequences $3^{\prime}$ to an $\mathrm{XbaI}$ site located $\sim 500$ bp beyond the fusion junction abolished activation, whereas deletion of sequences beyond the distal BamHI site had no effect (Fig. 1). These data indicate 

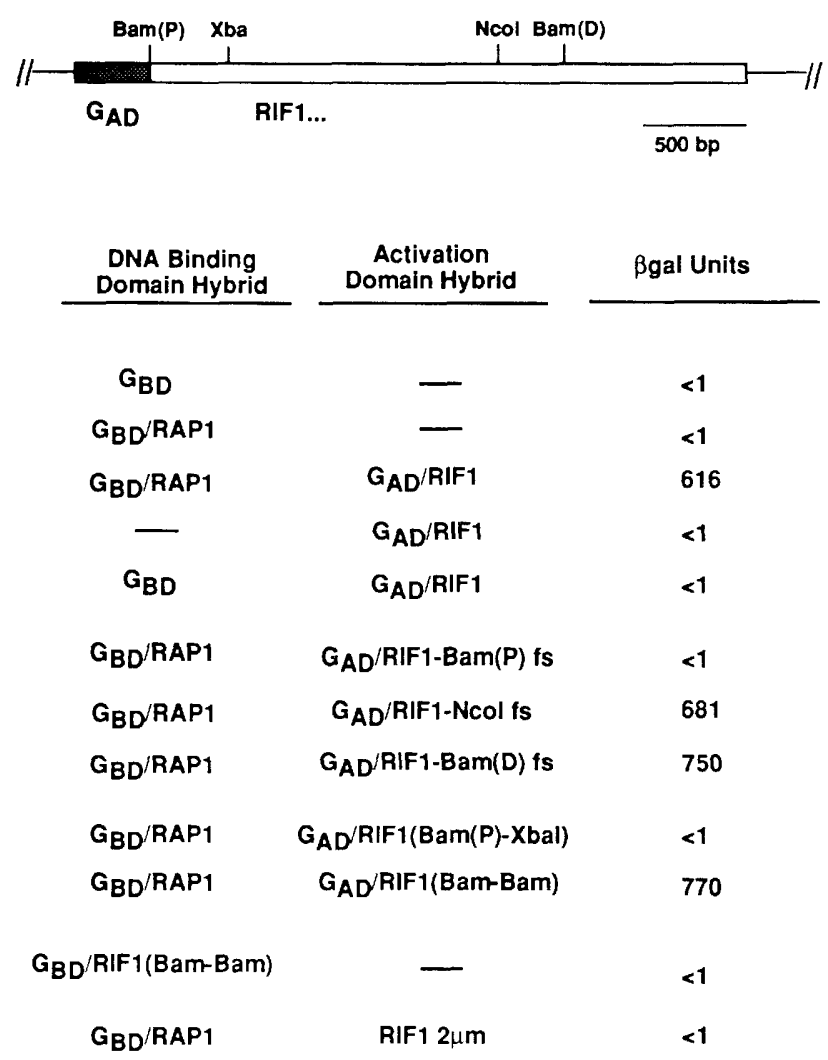

Figure 1. Isolation of a plasmid encoding a RAPl-interacting protein using the two-hybrid system. A plasmid $\left(\mathrm{G}_{\mathrm{AD}} / \mathrm{RIF} 1\right)$ was isolated from a library of fusions in the expression vector pGAD2 on the basis of its ability to activate a GAL1-lacZ reporter gene in the presence of the $\mathrm{G}_{\mathrm{BD}} / \mathrm{RAP}(653-827)$ hybrid (see Material and methods|. A partial restriction map of $\mathrm{G}_{\mathrm{AD}} / \mathrm{RIFl}$ is shown above. Quantitative $\beta$-galactosidase assays were conducted on a variety of strains transformed with the designated plasmids, and the average of four independent transformants is given. All the strains contain $2-\mu \mathrm{m}$-based high copy number plasmids. The $\mathrm{G}_{\mathrm{BD}}$ hybrids are expressed from the strong $A D H 1$ promoter, whereas the $\mathrm{G}_{\mathrm{AD}}$ hybrids are expressed from a cryptic promoter, perhaps lying within the $A D H 1$ terminator fragment. $\mathrm{G}_{\mathrm{AD}} / \mathrm{RIF}[\operatorname{Bam}(\mathrm{P})-\operatorname{Bam}(\mathrm{D})]$ and $\mathrm{G}_{\mathrm{AD}} / \operatorname{RIF}[\operatorname{Bam}(\mathrm{P})-\mathrm{XbaI}]$ contain the corresponding restriction fragments from the original $G_{A D}$ / RIF1 isolate cloned into the pGAD2 vector /see Materials and methods|. RIF1 $2 \mu \mathrm{m}$ contains the full-length RIF1 gene, including putative upstream promoter sequences, on a $2-\mu \mathrm{m}$-based LEU2-containing plasmid.

that the RIF1 sequences necessary and sufficient for an interaction with the RAP1 carboxyl terminus are located upstream of the NcoI site and that the sequences contained on the small BamHI-XbaI fragment are not sufficient for this interaction. Activation by $\mathrm{G}_{\mathrm{AD}} / \mathrm{RIF} 1$ is also dependent on the $\mathrm{G}_{\mathrm{AD}}$ portion of the hybrid because a $\mathrm{G}_{\mathrm{BD}} / \mathrm{RIF} 1$ hybrid, which targets the carboxy-terminal part of RIFl from the original $\mathrm{G}_{\mathrm{AD}} / \mathrm{RIF} 1$ hybrid to the reporter gene, does not result in activation (Fig. 1). Furthermore, overexpression of full-length RIFl (from a $2-\mu \mathrm{m}$ plasmid containing the complete gene) in the presence of the $\mathrm{G}_{\mathrm{BD}} / \mathrm{RAPl}(653-827)$ hybrid does not result in activation of the reporter gene (Fig. 1; RIFl $2 \mu \mathrm{m}$ ).

\section{Isolation and DNA sequence of the RIF1 gene}

Using the proximal BamHI-XbaI RIF1 fragment to probe a yeast genomic library, a large overlapping clone of $\sim 8.0$ $\mathrm{kb}$ was obtained. The DNA sequence of $6.5 \mathrm{~kb}$ of this fragment was determined and is shown in Figure 2. The sequence contains a single large open reading frame that could encode a protein of 1916 amino acids with a molecular mass of $219 \mathrm{kD}$. Although this open reading frame contains the splicing signal $5^{\prime}$-TACTAAC- $3^{\prime}$ lat nucleotide 4947), we found no nearby match to the conserved $5^{\prime}$ splice site sequence $\left(5^{\prime}\right.$-GTATGT-3') (Guthrie 1991 and references therein). Northern analysis of both total and poly(A)-selected RNA shows that this $8.0-\mathrm{kb}$ fragment hybridizes to an $\sim 6.3$-kb RNA, consistent with the $5.8-\mathrm{kb}$ open reading frame present in the fragment (data not shown). The RIFl sequence present in the $\mathrm{G}_{\mathrm{AD}}$ / RIF1 hybrid begins at amino acid 1614 of the predicted protein, indicating that a carboxy-terminal portion of RIF1 is sufficient to interact with RAP1. We failed to find any strong similarities between the predicted RIF 1 protein and sequences present in available protein data bases (for details, see Material and methods), and the protein sequence does not appear to indicate any distinctive structural features. Interestingly, there is a single MluI site (ACGCGT) in the 6.5 -kb sequence (at nucleotide 262 ), $\sim 200 \mathrm{bp}$ upstream of the putative initiator ATG of RIF1. MluI sites are often found within the promoters of genes whose mRNA levels increase at the $G_{1} /$ S-phase boundary (Andrews and Herskowitz 1990). Several genes encoding DNA replication proteins contain one or two MluI sites in their upstream regions, and these sites appear to be at least in part responsible for their cell cycle-regulated transcription (Pizzagalli et al. 1988; Bauer and Burgers 1990; Brill and Stillman 1991; Lowndes et al. 1991).

\section{Disruption of the RIF1 gene affects silencing}

To examine directly the in vivo function of RIF1, the cloned gene was used to construct a disruption of the chromosomal copy. An MluI-XbaI fragment of RIF1 (Fig. 2, base pairs $262-5685$ ) was deleted and replaced by a fragment containing the URA3 gene. This results in deletion of $>90 \%$ of the predicted $R I F 1$ open reading frame and removes all of the amino-terminal coding sequences. Initially, a ura3- homozygous diploid was transformed with this construct. Ura ${ }^{+}$transformants were selected and screened by Southern blotting for those in which a single copy of the gene had been replaced by the rif1::URA3 deletion/substitution. Four different isolates with the appropriate structure were sporulated, and most tetrads yielded four viable spores with $U R A 3$ segregating $2: 2$, indicating that $R I F 1$ is not an essential gene (data not shown). The growth of rif1::URA3 cells on YEPD plates is indistinguishable from isogenic RIF1 cells, indicating that RIF1 is not required for any essential transcriptional activation functions mediated by RAP1.

To determine whether rif1::URA3 mutants are defective in silencing, the effects of the RIF1 disruption at the 
Downloaded from genesdev.cshlp.org on April 26, 2023 - Published by Cold Spring Harbor Laboratory Press

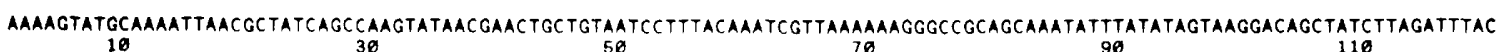

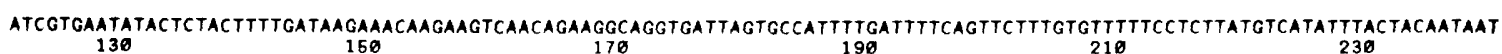
130

190

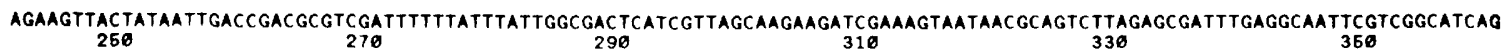

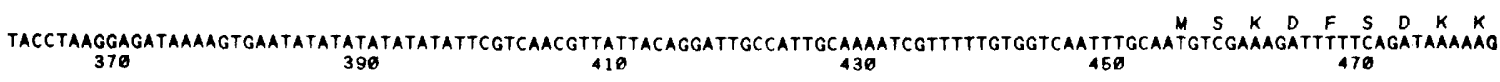

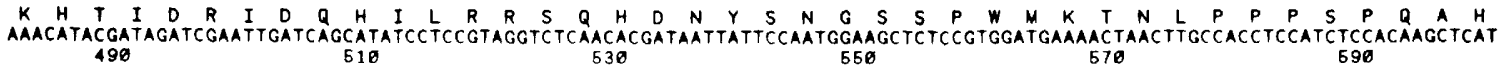

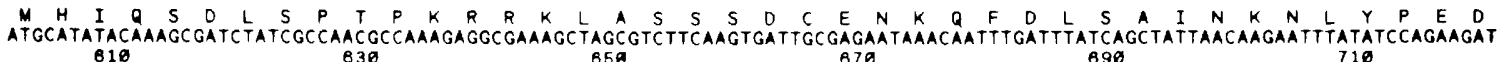
ACAGGAAGCAGGCTAATGCAAAGTCTTCCAGAGTTGTCTGCCTCTAATAGTGATAATGTATCACCGGTTACAAAAAGTGTAGCTTTTTCTGATAGGATAGAATCATCACCGATTTACCGC

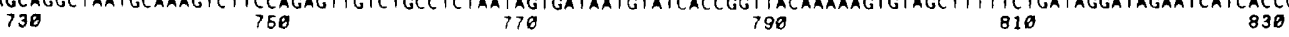

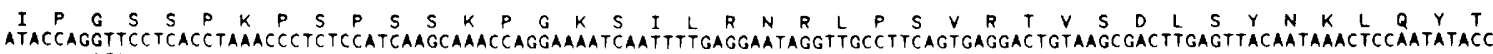
850

CAACACAAATTACACAACGGTAATATTTTCACATCACCTTATAAGGAAACAAGGGTAAATCCTCGCGCCTTAGAGTATTGGGTGAGTGGTGAGATCCATGGTTTAGTTGATAATGAAAGT 970 990

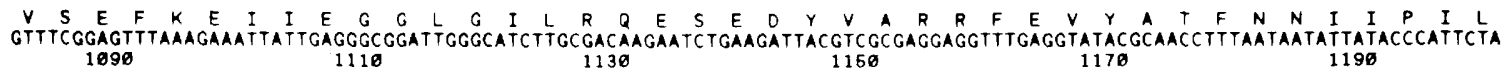
A'CÁTTAAAAATGTTAACGAGGTTGATCAGAAATTCAATATTCTAATTGTGAATATAGAAAGTATCATTGAAATATGCATACCGCATCTACAAATAGCACAGGACACATTATTAAGTAGT 1210 1230

S E K K N N P F V V I R L Y V V Q I V R F F S A I M S N F K I V K W L T K R P D L V N 1336

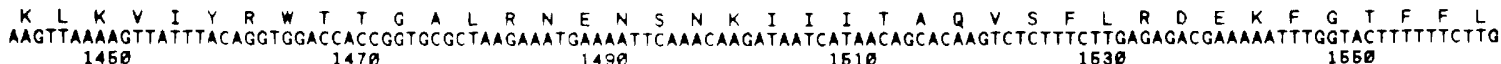
S N E E I K K P I I S T F T' E I M E I N S H N L I Y E K L L L L I R G F L S K Y Y P K $\begin{array}{ccccc}1578 & 1598 & 1610 & 1838 & 1650\end{array}$ T'TAATGATTGAGACGGTAACTTCTTGGTTACCAGGTGAGGTACTACCTAGGATTATTATCGGAGATGAAATTAACTCCATGAAAATTCTCATAACTTCAATAGTTGTTTIACTGGAACTA 189001710 1790

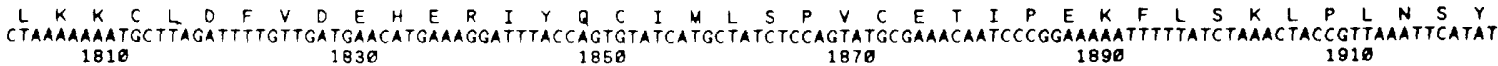

D S A N L
GACAGCGCTAATTIAGATAAAGTGACAATTGGTCATCTTCTTACACAGCAGATAAAAAACTATATTGTGGTCAAAAATGACAATAAAATAGCAATGGATTTGTGGCTITCAATGACCGGA
1930

TLACTATACGATAGCGGAAGAAGATTTATGATTTGACATCAGAATCTAACAAAGTTTGGTTTGATTTAAATAACCTGTGCTTTATCAATAATCACCCCAAGACTCGCTTAATGTCCATC 2070 (c) 211 B 2130 2150

KAAGTTTGGAGAATTATTACCTACTGCATATCCACGAMAATATCACAGAAAAATCAGGAAGGAACAAAAGTTTACTGTCACTTTTACGAACCCCTTTTCAAATGACGCTTCCTTATGTG 2170 2190 ORAGAAATATCACAGAAAA 2238 2560 (2270

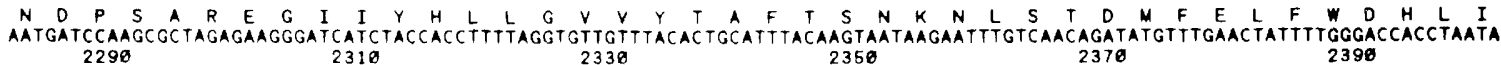
ACCCCGATTTATGAAGATTATGTTTTCAAATATGATTCGATTCACTTGCAAAATGTACTCTTCACAGTTTIGCATTTGTTAATTGGGGGAAAGAATGCAGATGTTGCATTGGAAAGAAAA 2410 2430 OATATTCATTCACTTOCA 2450 2478 2510

Y $K \underset{K}{K}$ K H I H H P M S V V I A S E G V V K 2530
2550

F

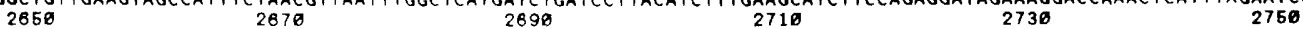

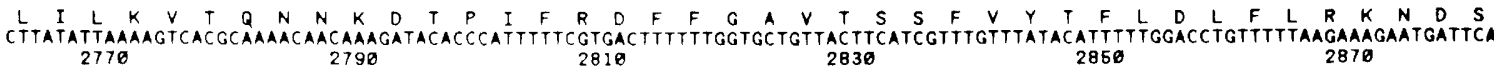

SCATTAGTAAATTTCAATATCCAAATTTCCAAAGTTGGTATTTCGCAAGGAACATGACCCTTGATCTTTTAAAAGATGTTATCAGGAAAGCTCGAAACGAAACATCTGAATTTCTGATA 2890 2910 2958 2996

I E K F L E E L D D D K K K T E V Y Y A Q N N V G S T L L L P N I S F R E F Q S L L A N I 3010 3030 300 3050

$V N$ K V V
GTGAACAAATTCCGAATGAAAATTCCATTGAAAATTTCTTGGACCTATGTTTGAAGCTCAGCTTTCCAGTTAATTTGTTTACACTACTTCATGTGTCTATGTGGTCGAACAATAATTTT
3130

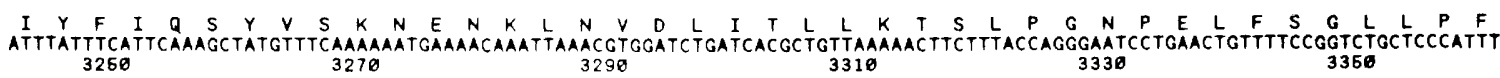

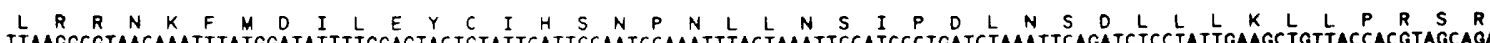

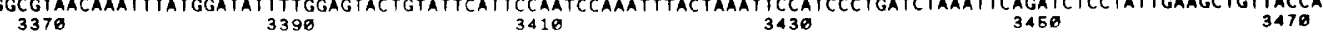

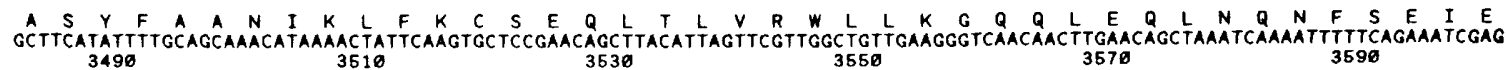

Figure 2. (See facing page for legend.) 


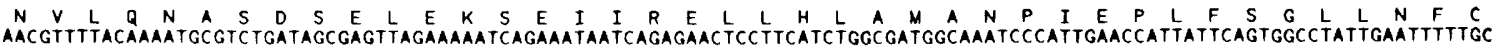

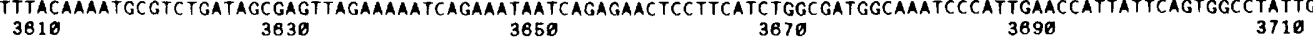

I K N N M A D H L D E F C G N M T S E V L F K I S P E L L L L K L L L T Y K E K P N 3730
3750

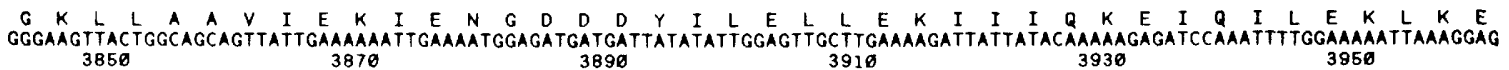

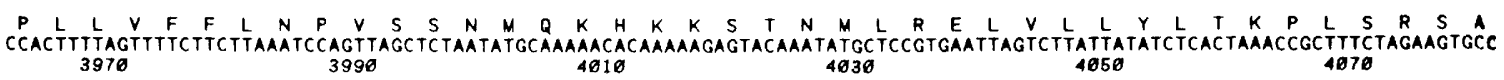

GCCAAAAAATTTTTTCCATGTTAATTAGTATATTACCGCCAAACCCTAACTATCAAACTATTGATATGGTTAATCTGTTGATTGACCTCATCAAATCACATAATCGTAAGTTTAAAGAT

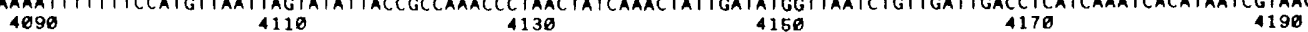

AAGAGAACCTATAATGCAACATTAAAGACAATAGGAAAGTGGATACAGGAATCGGGCGTGGTTCATCAAGGGGACTCAAGTAAGGAATTGAAGCTATACCTGACACTAAGTCGATGTAT

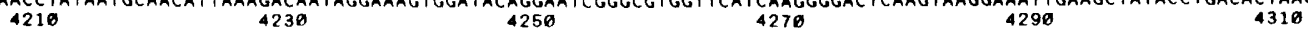

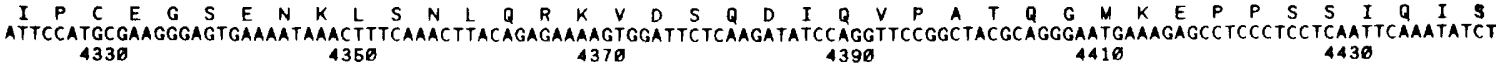

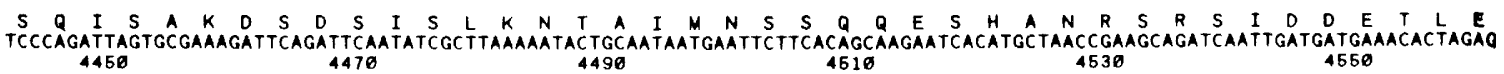

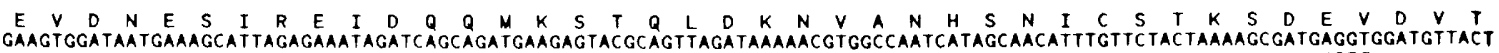

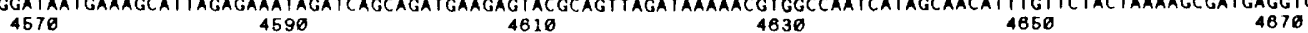

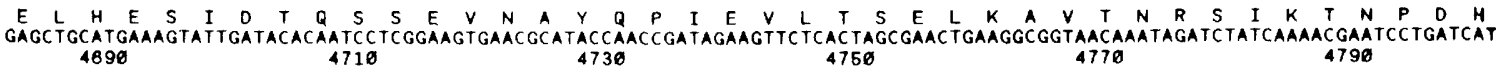

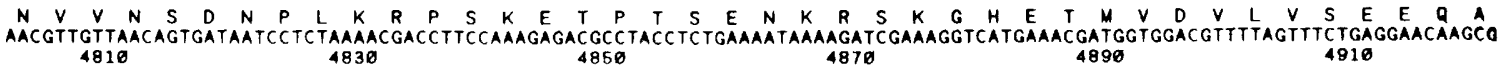

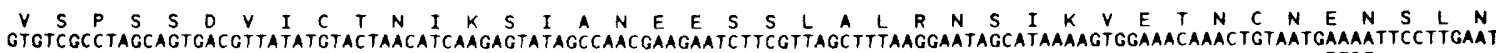
4930

GTCACTTTAGATCTCGACCAGCAAACCATAACAAAGGAaGATGGAaAAGGGCAAGTTGAACATGTTCAAAGACAGGAGAACCAGGAAGTATGAATAAAATCAACAGTAAAAGTTTTACG БE58

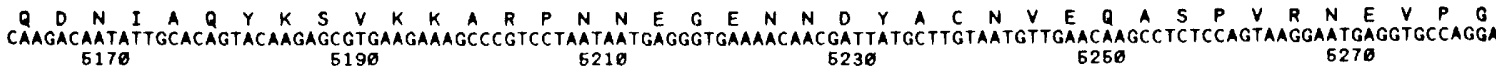

GaCGGCATTCAGATCCCGAGTGGGACTATACTTCTCAATAGTTCAAAGCAGACAGAAAAATCAAAAGTTGATGACTTGCGTAGTGATGAAGATGAACATGGAACGGTTGCGGCAAGAGAAA 5290

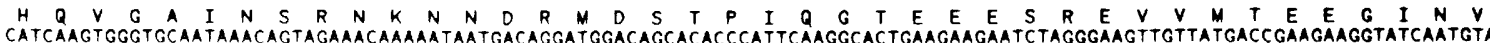

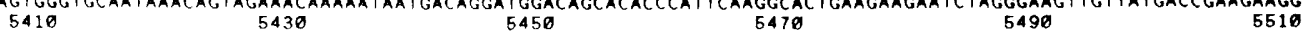

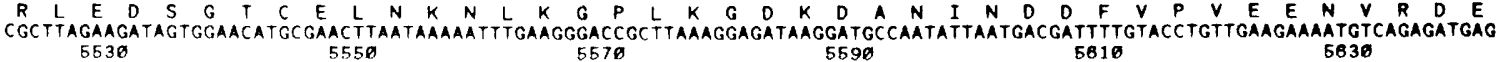

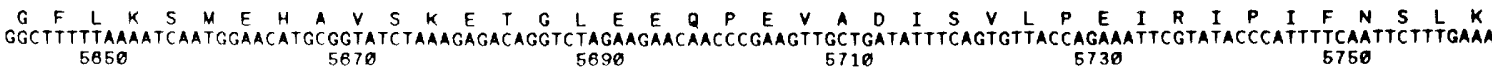

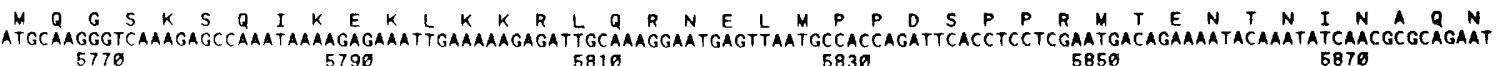

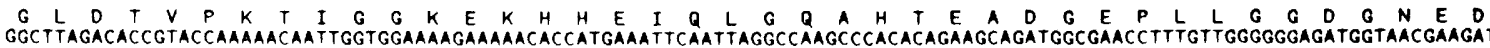
5890 5910 5930

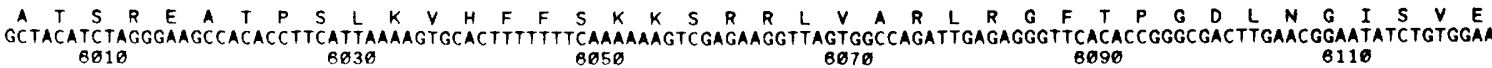

E R R N L R I E L L L D F M M R L E E Y Y S N R P N N

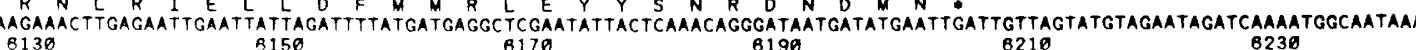

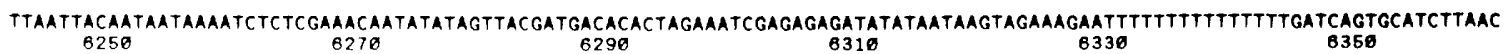

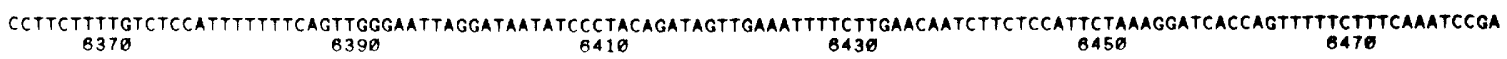

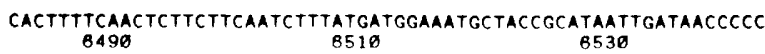

Figure 2. Nucleotide and deduced amino acid sequence of the RIF1 gene. The DNA sequence shown begins 454 bp upstream of the putative translational start site (first methionine) of RIFl and extends 337 bp beyond the TGA termination codon. The predicted amino acid sequence of RIF1 is shown in the one-letter code.

$H M R$ locus were assayed. Because the HMRE silencer is a redundant regulatory element, it was necessary to $\mathrm{cx}$ amine a wild-type silencer and two different mutated silencers that retain complete function. In addition to the RAP1-binding site, the HMRE silencer contains two other regulatory sites (called $\mathrm{A}$ and $\mathrm{B}$ ), either one of 
Hardy et al.

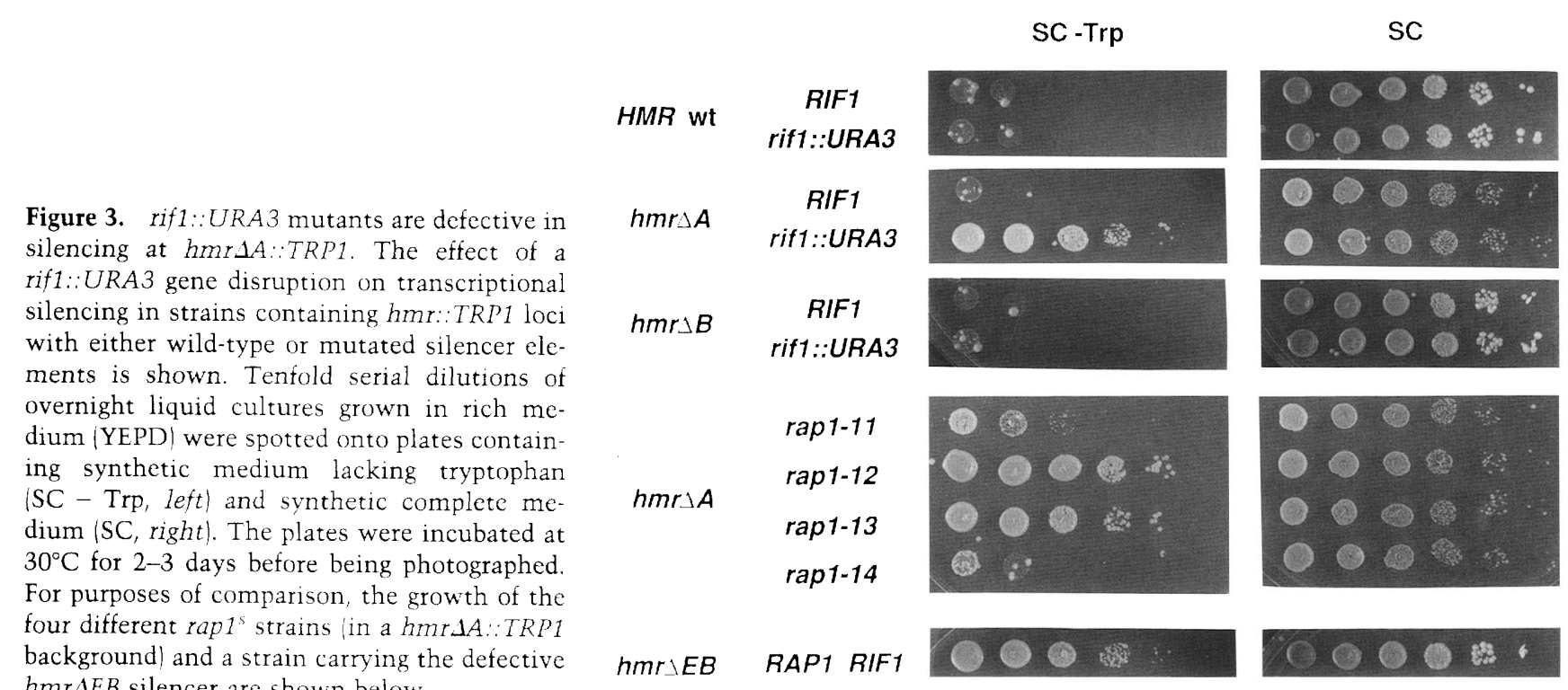

which, together with the RAPl site $\langle E\rangle$, is sufficient for complete repression (Brand et al. 1987; Kimmerly et al. 1988). The A element is an autonomously replicating sequence (ARS) consensus element, whereas the B element is a binding site for the ABFl protein (Shore et al. 1987; Buchman et al. 1988a). We noted previously that rap $1^{s}$ mutants display a defect in silencing only when the A element at $H M R$ is deleted $(h m r \Delta A)$ Sussel and Shore 1991). Furthermore, the hmr $\Delta A$ silencer is affected most severely by overexpression of $\mathrm{G}_{\mathrm{BD}} / \mathrm{RAPl}$ hybrids (Hardy et al. 1992).

To assay for silencer function, strains in which the TRP1 gene has been placed at HMR (Miller et al. 1984; Brand et al. 1985/ were used. The ability of such strains to grow in the absence of tryptophan is a sensitive and accurate assay for the loss of silencer function (Sussel and Shore 1991). Haploid strains containing hmr::TRP1, $h m r \Delta A:: T R P 1$, or hmr $\triangle B:: T R P 1$ silencers were transformed with rif1::URA3 DNA and screened by Southern blotting for the correct chromosomal disruption. Analysis of these strains showed that only the hmr $A A:: T R P 1$ silencer strain was affected by the chromosomal disruption of RIF1 and was thus able to grow in the absence of tryptophan (Fig. 3). Furthermore, the derepression of hmr $\triangle A:: T R P 1$ caused by the rif1::URA3 mutation was complete and indistinguishable from that of the strong rap $1^{\text {s }}$ alleles, rap1-12 and rap1-13. Strains containing a wild-type silencer (hmr::TRP1) or a $\Delta B$ silencer (hmr $\Delta B:: T R P 1)$ showed normal repression of the TRP1 reporter gene in the presence of the rif $1:: U R A 3$ disruption.

\section{RIFl affects telomere length regulation}

To determine whether RIF1 plays a role at telomeres, as does RAP1, Southern blot analysis was used to measure the average length and heterogeneity of telomeres from the rif $1:: U R A 3$ mutant strains. Total yeast genomic DNA was digested with XhoI and probed with radiolabeled poly $[\mathrm{d}(\mathrm{G}-\mathrm{T})] \cdot$ poly$[\mathrm{d}(\mathrm{A}-\mathrm{C})]$, which hybridizes with the terminal poly $\left(\mathrm{C}_{1-3} \mathrm{~A}\right)$ sequences (Shampay et al. 1984; Walmsley et al. 1984). A prominent heterogeneous band of $\sim 1.2 \mathrm{~kb}$ results from the large number of yeast telomeres that contain a subtelomeric $\mathrm{Y}^{\prime}$ element. As shown in Figure 4, rif $1:$ URA3 mutants display a significant increase in the average length of this terminal fragment $(\sim 200-300 \mathrm{bp})$, as compared to the wild-type parent strain. We presume that this results from an increase in the length of the poly $\left(\mathrm{C}_{1-3} \mathrm{~A}\right)$ sequences within these fragments. In addition, the heterogeneity in length of the chromosome ends appears to increase in rif $1:: U R A 3$ strains relative to their wild-type parent. This effect is very similar to the telomere lengthening displayed by the silencing-defective rap1-12 and rap1-13 mutants (Fig. 4).

\section{A carboxy-terminal domain of RAP1 required for $R I F 1$ binding}

A previously characterized series of $\mathrm{G}_{\mathrm{BD}} / \mathrm{RAPl}$ hybrids (Hardy et al. 1992) was used to determine which RAP1 sequences in $\mathrm{G}_{\mathrm{BD}} / \mathrm{RAPl}$ are required for $\mathrm{G}_{\mathrm{AD}} / \mathrm{RIF1-de-}$ pendent activation of the GAL1-lacZ reporter gene. Figure 5 shows that there is a very close correlation between the sequences required for derepression by $\mathrm{G}_{\mathrm{BD}} / \mathrm{RAP} 1$ and those required for an interaction with $\mathrm{G}_{\mathrm{AD}} / \mathrm{RIF}$. For example, $\mathrm{G}_{\mathrm{BD}} / \mathrm{RAPl}(653-827)$ and $\mathrm{G}_{\mathrm{BD}} / \mathrm{RAP} 1(655-827)$ both completely derepress the $h m r \triangle A:: T R P 1$ locus and cooperate with $\mathrm{G}_{\mathrm{AD}} / \mathrm{RIF} 1$ to give comparable levels of $\beta$-galactosidase expression. In addition, the $\mathrm{G}_{\mathrm{BD}} /$ RAPl(679-827) hybrid displays a reduced ability to both derepress $\left[\sim 10\right.$ - to 20 -fold lower than $\mathrm{G}_{\mathrm{BD}} / \mathrm{RAP} 1 / 653$ 827) and $\left.\mathrm{G}_{\mathrm{BD}} / \mathrm{RAP} 1(655-827)\right]$ and to participate in $\mathrm{G}_{\mathrm{AD}} /$ RIF1-dependent activation (36 units, compared with 616 

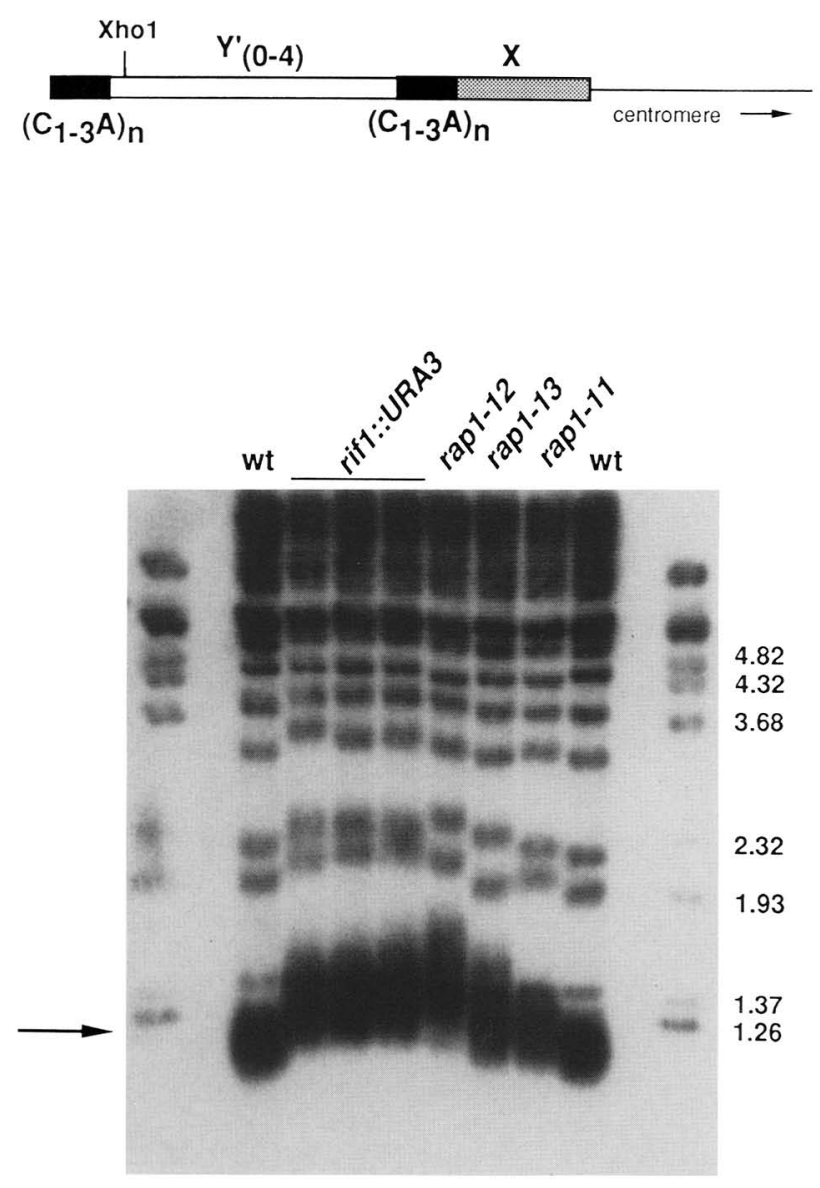

Figure 4. Telomeric poly $\left(\mathrm{C}_{1-3} \mathrm{~A}\right)$ tracts are lengthened in rif1::URA3 mutants. (A) Schematic representation of yeast telomeres. Note that many, but not all, telomeres contain the $\mathrm{Y}^{\prime}$ element, which has a $X$ hoI site near the poly $\left(\mathrm{C}_{1_{-3}} \mathrm{~A}\right)$ tract. $(B)$ Southern analysis. Xhol-digested genomic DNA from the indicated strains was probed with ${ }^{32}$ P-labeled poly[d(G-T) - d (C-A $\left.)\right]$. A heterogeneous band of $\sim 1.2 \mathrm{~kb}$ in the wild-type strain (indicated by the arrow) arises from the many yeast telomeres that contain at least one $\mathrm{Y}^{\prime}$ element.

and 895 units). Finally, all of the additional hybrids that we examined are completely defective in both activities (Fig. 5, rows 5-11). Taken together, these results indicate that both derepression and $\mathrm{G}_{\mathrm{AD}}$ / RIF1-dependent activation by $\mathrm{G}_{\mathrm{BD}} / \mathrm{RAPl}$ hybrids require the same carboxyterminal domain of RAPl.

\section{Silencing-defective rap $1^{\mathrm{s}}$ mutants are defective in $G_{A D} / R I F 1$-dependent activation}

Having shown that a carboxy-terminal part of RAP1, whose overexpression causes derepression, is necessary for a RAP1-RIF1 interaction, we then asked whether silencing-defective point mutations in this region of RAP1 disrupt the RAP1-RIF1 interaction. To answer this question we made use of four different rap $1^{s}$ alleles that contain either single or double missense mutations in the RAP1 carboxyl terminus, affecting amino acids 726,727 , and 747 (Sussel and Shore 1991). The rap1 ${ }^{s}$ mutants cause either strong (rap1-12 and rap1-13) or weak (rap111 and rap1-14) derepression of the $h m r \Delta \mathrm{A}:$ :TRP1 locus and variable elongation of poly $\left(\mathrm{C}_{1-3} \mathrm{~A}\right)$ tracts at telomeres. A series of four $\mathrm{G}_{\mathrm{BD}} / \mathrm{rapl}^{\mathrm{s}}(653-827)$ hybrids were constructed that incorporated the mutant changes of the rap $1^{s}$ alleles into the $\mathrm{G}_{\mathrm{BD}} / \mathrm{RAP} 1(653-827)$ hybrid. These $\mathrm{G}_{\mathrm{BD}} / \mathrm{rap} 1^{\text {s }}$ hybrids were then coexpressed with the $\mathrm{G}_{\mathrm{AD}} /$ RIF1 hybrid in the GAL1-lacZ reporter strain.

As shown in Table 1, there is a striking inverse correlation between the extent of derepression caused by the different rap $1^{s}$ alleles and the ability of the corresponding $\mathrm{G}_{\mathrm{BD}} / \mathrm{rapl}^{\mathrm{s}}$ hybrids to activate the GAL1-lacZ reporter when expressed together with $\mathrm{G}_{\mathrm{AD}} / \mathrm{RIF1}$. The two strong rap $1^{\text {s }}$ mutants, rap1-12 and rap1-13, are both completely defective in silencing the $h m r \triangle A:: T R P 1$ locus and also fail to activate in conjunction with $\mathrm{G}_{\mathrm{AD}} / \mathrm{RIF1}$. Perhaps more significant is the observation that the weak rap $1^{\text {s }}$ alleles (rap1-11 and rap1-14, with only a partial defect in silencing of $h m r \Delta A:: T R P 1)$ display a measurable but reduced ability as $\mathrm{G}_{\mathrm{BD}} / \mathrm{rap}^{\text {s }}$ hybrids to interact with $\mathrm{G}_{\mathrm{AD}} / \mathrm{RIF1}$. These results suggest that the strong rap $1^{\text {s }}$ mutants have a totally defective RIF1 interaction site, whereas the weak rap $1^{s}$ mutants retain a partially functional RIF1 interaction site. Furthermore, they signify that the defect in silencing by the $\operatorname{rap} 1^{s} \mathrm{mu}$ tants may be explained by a failure to interact with RIF1. Interestingly, though, the $\mathrm{G}_{\mathrm{BD}} / \mathrm{rap}^{\text {s }}$ hybrids derepress the $h m r \triangle A:: T R P 1$ locus to the same extent as the $\mathrm{G}_{\mathrm{BD}} /$ $\operatorname{RAP}(653-827)$ hybrid from which they were derived (data not shown; see Discussion).

\section{Isolation of a $G_{A D} /$ rif1 mutant that partially restores an interaction with $G_{B D} /$ rap $1^{\text {s }}$ hybrids}

We reasoned that if $\operatorname{rap} 1^{\mathrm{s}}$ proteins were defective in an interaction with RIF1, then mutations in RIF1 may suppress this defect. The two-hybrid system was utilized further to screen for a mutated $\mathrm{G}_{\mathrm{AD}} /$ rifl hybrid that could suppress the activation defect of the $\mathrm{G}_{\mathrm{BD}} / \mathrm{rapl} 1^{\mathrm{s}}$ hybrids. The $\mathrm{G}_{\mathrm{AD}} / \mathrm{RIF} 1$ plasmid was mutagenized by passage through an Escherichia coli mutD5 strain (see Materials and methods) and transformed into a GAL1lacZ reporter strain expressing $\mathrm{G}_{\mathrm{BD}} / \mathrm{rap} 1-12$, which is completely defective in $\mathrm{G}_{\mathrm{AD}}$ /RIFl-mediated activation (see Table 1). From $>15,000$ transformants, one plasmid was obtained that conferred a blue colony color on X-gal plates and thus appeared to suppress the $\mathrm{G}_{\mathrm{BD}} / \mathrm{rap} 1-12$ activation defect. The plasmid, encoding what will be referred to as $\mathrm{G}_{\mathrm{AD}} / \mathrm{rif1}-1$, was retransformed into the reporter strain coexpressing the original $\mathrm{G}_{\mathrm{BD}} / \mathrm{RAP} 1$ /653827) hybrid and into strains coexpressing each one of the four different $\mathrm{G}_{\mathrm{BD}} / \mathrm{rapl}^{\mathrm{s}}$ mutant derivatives of this hybrid. Interestingly, the $\beta$-galactosidase levels for each strain converged to an intermediate value between 100 and 200 units, less than one-third of the value obtained with the two wild-type hybrids, $\mathrm{G}_{\mathrm{BD}} / \mathrm{RAPl}$ and $\mathrm{G}_{\mathrm{AD}} /$ RIF1 (Table 2). The mutation was mapped to the RIF1 part of the $\mathrm{G}_{\mathrm{AD}} / \mathrm{RIFl}$ hybrid by exchanging restriction fragments with the wild-type $G_{A D} / R I F 1$ plasmid and 


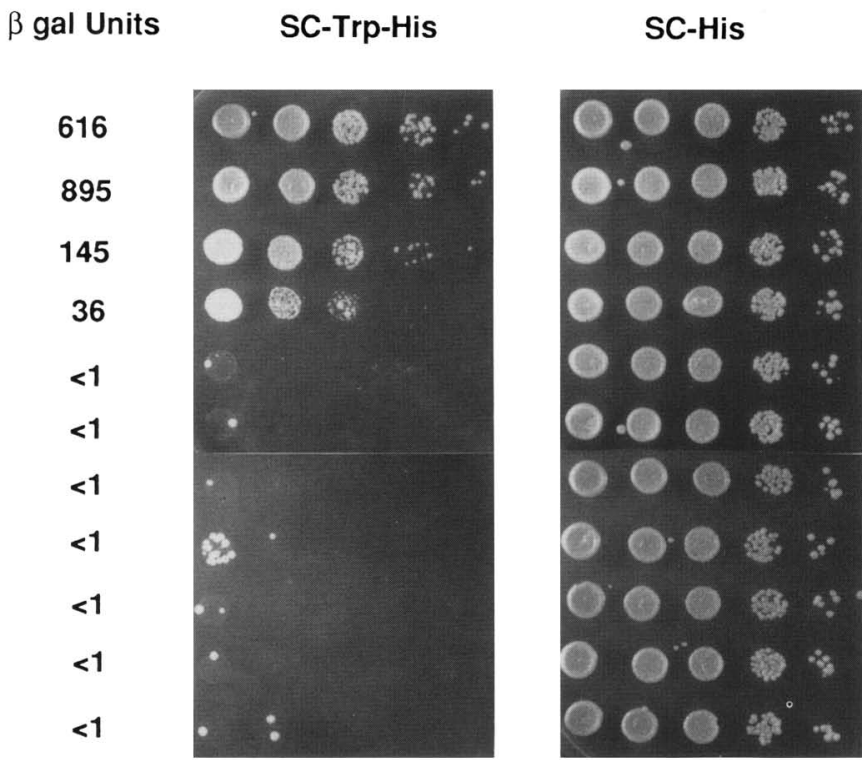

Figure 5. RIF1 interacts with a carboxy-terminal domain of RAPl. A series of $\mathrm{G}_{\mathrm{BD}} / \mathrm{RAPl}$ hybrids was assayed for the ability to interact with the $\mathrm{G}_{\mathrm{AD}} / \mathrm{RIF} 1$ hybrid and to activate the GAL1-lacZ reporter gene. Quantitative $\beta$-galactosidase assays were performed for strains containing both the indicated $\mathrm{G}_{\mathrm{BD}} / \mathrm{RAP}$ plasmids and the $\mathrm{G}_{\mathrm{AD}} / \mathrm{RIF} 1$ plasmid isee Fig. 1 and Materials and methods|. The $\mathrm{G}_{\mathrm{BD}} /$ RAP-expressing plasmids were also assayed for their effect on silencing at the hmr. $A::$ TRP1 locus (see Fig. 3; Hardy et al. 1992).

was identified by DNA scquencing as a $G \rightarrow$ A change at nucleotide 6169 (Fig. 2). This mutation would be predicted to result in a change from glutamic acid to lysine at amino acid 1906 of RIF1, only 10 codons from the carboxyl terminus of the protein.

Two features of the $\mathrm{G}_{\mathrm{AD}} /$ rif1-1 mutant hybrid are worth emphasizing. First, the mutant hybrid appears to interact less well with the wild-type $\mathrm{G}_{\mathrm{BI}}$ / $\mathrm{RAPl}$ hybrid than does the wild-type $\mathrm{G}_{\mathrm{AI}}$ / RIFl hybrid, as shown by the significantly lower $\beta$-galactosidase value. This result indicates that the $\mathrm{G}_{\mathrm{AD}}$ /rif1-1 mutant does not work by simply raising the affinity for wild-type RAP1 and thus compensating for a defect in rapl-12. Second, although the rifl-1 mutant is not allele specific, that is, it improves the interaction with both the rapl-13 and rap 1-14 hybrids, it has the striking property of appearing to interact approximately equally well with all four mutant rapl ${ }^{\text {s }}$ hybrids and with the wild-type $\mathrm{G}_{\mathrm{BD}} / \mathrm{RAPl}$ hybrid. This property is in marked contrast to the ability of the

Table 1. $G_{B D} /$ rap $1^{s}$ mutant hybrids are defective in $G_{A D} / R I F 1$-dependent activation

\begin{tabular}{lcc}
\hline $\begin{array}{l}\text { DNA-binding } \\
\text { domain hybrid }\end{array}$ & $\begin{array}{l}\beta \text {-gal } \\
\text { units }\end{array}$ & $\begin{array}{l}\text { Silencing defect } \\
\text { in context of } \\
\text { full-length RAP1 }\end{array}$ \\
\hline $\mathrm{G}_{\mathrm{BD}} /$ RAP1 & 616 & none \\
$\mathrm{G}_{\mathrm{BD}} /$ rapl-11 & 172 & weak \\
$\mathrm{G}_{\mathrm{BD}} /$ rapl-12 & $<1$ & strong \\
$\mathrm{G}_{\mathrm{BD}} /$ rapl-13 & $<1$ & strong \\
$\mathrm{G}_{\mathrm{BD}} /$ rapl-14 & 35 & weak \\
$\mathrm{G}_{\mathrm{BD}}$ & $<1$ & \\
\hline
\end{tabular}

$\mathrm{G}_{\mathrm{AD}} / \mathrm{RIF1}$ hybrid to distinguish between wild-type $\mathrm{G}_{\mathrm{BD}} /$ RAP1 and the two classes of rap ${ }^{s}$ hybrids. The failure of the $\mathrm{G}_{\mathrm{AD}} /$ rifl-1 hybrid to distinguish between $\mathrm{G}_{\mathrm{BD}} / \mathrm{RAPl}$ and the different $\mathrm{G}_{\mathrm{BD}} / \mathrm{rap}^{\mathrm{s}}$ hybrids suggests that the rif 1-1 mutation may abolish a specific interaction with RAPl, defined at least in part by codons 726,727 , and 747 in RAP1, rather than compensating for the alteration in the rap1-12 mutant.

\section{Discussion}

We have isolated a novel gene, RIF1, on the basis of the ability of a portion of its protein product to associate with the RAP1 carboxyl terminus in vivo. Loss of RIF1 function results in derepression of an $H M R$ silencer, whose ARS consensus element has been deleted, and in the elongation of telomeres, two properties characteris-

Table 2. The $G_{A D} /$ rif1-1 mutant suppresses the activation defect of $G_{B D} /$ rap $1^{5}$ mutants

\begin{tabular}{lcc}
\hline & \multicolumn{2}{c}{ Activation domain hybrid } \\
\cline { 2 - 3 } $\begin{array}{l}\text { DNA-binding } \\
\text { domain hybrid }\end{array}$ & $\mathrm{G}_{\mathrm{AD}} / \mathrm{RIF}$ ( $)$ & $\mathrm{G}_{\mathrm{AD}} /$ rifl-1 \\
(B-gal units) \\
\hline $\mathrm{G}_{\mathrm{BD}} / \mathrm{RAPl}$ & 616 & 165 \\
$\mathrm{G}_{\mathrm{BD}} /$ rapl-12 & $<1$ & 110 \\
$\mathrm{G}_{\mathrm{BD}} /$ rapl-13 & $<1$ & 177 \\
$\mathrm{G}_{\mathrm{BD}} /$ rapl-14 & 35 & 188 \\
$\mathrm{G}_{\mathrm{BD}} /$ rapl-1 & 172 & 126 \\
$\mathrm{G}_{\mathrm{BD}}$ & $<1$ & $\mathrm{ND}^{\mathrm{a}}$ \\
None & $<1$ & $<1$ \\
\hline
\end{tabular}

${ }^{a}$ Not determined. 
tic of silencing-defective rap $1^{5}$ alleles (Sussel and Shore 1991), confirming an involvement of RIF1 in both transcriptional silencing and telomere length regulation.

The genetic experiments presented here provide compelling evidence that the RAPl and RIFl proteins can physically associate and that this association is important for repression at $h m r \Delta A$ silencers and length regulation at telomeres. Activation by $\mathrm{G}_{\mathrm{AD}} / \mathrm{RIFl}$ would appear to depend on a physical association with the RAP1 carboxyl terminus. Furthermore, using the two-hybrid system, we have shown that $\mathrm{G}_{\mathrm{BD}} / \mathrm{rapl}^{\mathrm{s}}$ mutant hybrids interact poorly or not at all with $\mathrm{G}_{\mathrm{AD}} / \mathrm{RIFl}$. What is particularly striking is the strict correlation between the severity of the silencing defects of individual rap $1^{s} \mathrm{mu}$ tant alleles and the ability of the corresponding $\mathrm{G}_{\mathrm{BD}}$ / $\operatorname{rapl}^{\text {s }}$ hybrids to interact with the $\mathrm{G}_{\mathrm{AD}} / \mathrm{RIF1}$ hybrid. The two weakest rap $1^{s}$ alleles lead to an intermediate level of activation together with $\mathrm{G}_{\mathrm{AD}} / \mathrm{RIF} 1$, whereas the two strongest rap $1^{s}$ alleles fail to produce a detectable signal in the two-hybrid system. It seems unlikely that the $\mathrm{G}_{\mathrm{BD}} / \mathrm{rap} 1^{\mathrm{s}}$ defects reflect a general instability of the rap $1^{s}$ carboxy-terminal domains, as the rap $1^{s}$ mutants have both normal protein levels and do not display any temperature sensitivity (Sussel and Shore 1991). In addition, the $\mathrm{G}_{\mathrm{BD}} / \mathrm{rap}^{\mathrm{s}}$ hybrids are all capablc of silencer derepression, implying that they are also stable and properly folded (data not shown).

The propertics of the compensating $\mathrm{G}_{\mathrm{AD}} / \mathrm{rifl-1} \mathrm{mu}-$ tant argue strongly that there is a specific protein-protein interaction between RIF1 and the small carboxyterminal region of RAPl affected by the rap $1^{s}$ alleles. The $\mathrm{G}_{\mathrm{AD}} /$ rif 1-1 hybrid appears to interact less well with wild-type $\mathrm{G}_{\mathrm{BD}}$ / RAPl than does $\mathrm{G}_{\mathrm{AI}}$ /RIF1, implying that the rif1-1 mutation does not work by increasing the affinity of RIF1 for both wild-type RAPl and rap $1^{\mathrm{s}}$ proteins. Instead, we suggest that the rif 1-1 mutation alters a specific interaction with RAPl defined by the rap $1^{s}$ alleles, such that the rif1-1 protein can no longer distinguish between wild-type RAP1 and the four different rap $1^{\text {s }}$ mutants and thus interacts equally well with all of them. The properties of the rif 1-1 mutation are similar to those described for loss-of-contact mutations in sequence-specific DNA-binding proteins (Ebright et al. 1987). A simplificd model for the RAP1-RIF1 interaction, based on the mutant data, is shown schematically in Figure 6. The model predicts that the rap $1^{\text {s }}$ alleles lat amino acids 726,727 , and 747) define a specific interaction site on the RAP1 carboxyl terminus and that strong rap $1^{\text {s }}$ alleles (rap1-12 and rap1-13) create a repulsive interaction with RIF1 at this site that is abolished by the rif1-1 mutation. Further experiments, involving site-directed mutagenesis of both proteins, will test the validity of this proposal.

\section{RIF1: a co-factor or mediator for RAP1} at silencers and telomeres

Previous studies have identificd a large number of transacting regulators of silencing, including the four $S I R$

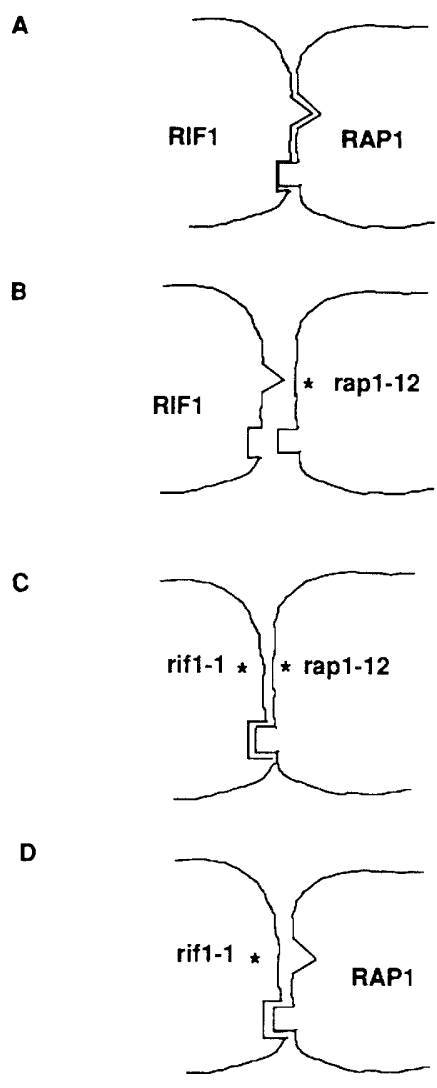

Figure 6. A model for the RAPl-RIFl interaction based on properties of mutant proteins in the two-hybrid system. $(A)$ The complementary triangular surfaces are intended to represent a proposed interaction site between RAPl and RIFl, defined in part by amino acids 726,726 , and 747 in RAP1 and amino acid 1906 in RIF1. The complementary rectangular surfaces represent the sum of all other RAP1-RIF1 interactions. The rap1-12 mutation creates an unfavorable interaction that significantly reduces or abolishes binding $(B)$. The rif1-1 mutation removes this unfavorable contact with rap1-12, allowing rifl-1 to interact equally well with rapl-12 and wild-type RAPl protein $(C, D)$. In the weaker alleles, rapl-14 and rapl-11, we imagine that the repulsive rap1-RIF1 interaction seen for the rapl-12-RIFl combination $(B)$ is either minimal (rapl-14) or essentially nonexistent $(\operatorname{rapl}-11)$.

genes (Haber and George 1979; Klar et al. 1979; Rine and Herskowitz 1987), HHF2 (encoding histone H4) (Kayne et al. 1988; Megee et al. 1990), NAT1 and ARD1 (encoding an amino-terminal protein acetyltransferase) (Whiteway et al. 1987; Mullen et al. 1989), CDC7 (Axelrod and Rine 1991), SUM1 (Klar et al. 1985; Livi et al. 1990; Laurenson and Rine 1991), RAP1 (Shore and Nasmyth 1987; Kurtz and Shore 1991; Sussel and Shore 1991), and presumably the gene encoding the other silencer binding factor ABF1 (Diffley and Stillman 1989; Halfter et al. 1989; Rhode et al. 1989; Francesconi and Eisenberg 1991). It is worth noting that in searching directly for a RAPl-interacting factor involved in silencing, we have identified a novel gene. Our results suggest that the con- 
nection between the silencer DNA-binding factors and other proteins responsible for silencing (e.g., histone $\mathrm{H} 4$ and SIR proteins) may be complex, involving RIFl and possibly other cofactors or mediators. Recent studies of transcriptional activation also point to intermediary factors in the interaction of DNA-binding activators and the basic transcriptional machinery (Dynlacht et al. 1991; Flanagan et al. 1991).

Data presented here are consistent with a model in which RAPl targets the binding of RIF1 to silencers and telomeres. We propose that this interaction leads to the recruitment of essential silencer factors le.g., SIR proteins), which themselves function as modifiers of chromatin structure at both silent mating-type loci and telomeres (Nasmyth 1982; Gottschling et al. 1990; Aparicio et al. 1991). It should be noted, however, that we cannot rule out a model in which RIFl modifies RAPl to allow it to function at silencers and telomeres but is itself not stably associated with these loci. It is possible that the proposed RAP1-RIFl interaction is restricted to silencer and telomere loci, because deletion of RIF1 has no effect on essential RAP1 transcriptional activation functions and RIFl interacts with a part of RAPl that may be important only at silencers and telomeres. One explanation for such a restriction is that RIF1 interacts with specific DNA sequences and/or other proteins found exclusively at silencers and telomeres. Modulation of the function of a DNA-binding regulatory protein by additional protein-protein and protein-DNA interactions occurs in other systems. For example, the MAT $\alpha 2$ repressor protein in yeast uses the MCMl protein, itself an activator in many contexts, as a corepressor at some loci through a combination of protein-protein interactions and sequence-specific DNA binding (Keleher et al. 1988,1989 ). One interpretation of our results is that RAP1 does not interact directly with any of the silencer factors identified previously (e.g., SIR 1-SIR4) and that its essential function in silencing at $h m r \Delta A$ is to target the binding of RIF1 to this locus, which then leads to the recruitment of SIR proteins. This idea can be tested in part by providing RIF 1 with a heterologous DNA-binding domain and targeting the resultant hybrid protein to a silencer containing the corresponding DNA-binding site and lacking a binding site for RAP1. Whether RIF1 is a mediator or a cofactor for RAPl at silencers and telomeres, it seems likely that it interacts with other factors at these loci (e.g., SIRs) and that such interactions will have important functional consequences.

A particularly notable feature of the HMRE silencer is its functional redundancy (Brand et al. 1987; Kimmerly et al. 1988; Stone et al. 1991). We noted recently that this redundancy extends to the RAPl protein itself iSussel and Shore 1991) because rap $1^{s}$ mutants do not affect the ability of the protein to contribute to repression of wildtype or $h m r \Delta B$ silencers. Because the rif1::URA3 mutants also display a silencing defect only when the A element (an ARS consensus sequence) is deleted at $H M R E$, RIF1 could function only for this one redundant RAP1 silencing function. This RIF1-associated silencing pathway is not required for either the wild-type or $h m r \Delta B$ silencers to work. With this in mind, one can imagine that RIF1 is required to stabilize interactions with replication factors (e.g., an ARS consensus sequence binding factor) at an $h m r \Delta A$ silencer, where a perfect match to the ARS consensus sequence is not present. In such a scheme, RIFl function may be needed only during the $S$ phase of the cell cycle, when the establishment of silencing is thought to occur (Miller and Nasmyth 1984). It will be interesting to determine whether RIF1 transcription is elevated during $S$ phase, as suggested by the presence of the MluI site upstream of the RIF1 gene.

Genes placed near telomeres are subject to a positioneffect repression (Gottschling et al. 1990) that requires many of the same trans-acting regulators necessary for silencing at $H M L$ and $H M R$ (Aparicio et al. 1991). However, telomeric silencing is metastable, a phenomenon seen at silent mating-type loci only in strains with certain cis- or trans-silencing mutations (Pillus and Rine 1989; Mahoney et al. 1991; Sussel and Shore 1991; L. Sussel and D. Shore, unpubl.) and is independent of SIR1 function (Aparicio et al. 1991). These observations have led to the suggestion that the silencers at $H M L$ and $H M R$ have additional redundant pathways for repression not present at telomeres (Aparicio et al. 1991). The silencing pathway defined by the rap $1^{s}$ and rif 1 mutations may not function at telomeres or it may also be redundant there. This may explain why rap $1^{s}$ mutants appear to have no effect on telomeric silencing (B. Billington and D. Gottschling, pers. comm.), despite the occurrence of many RAPl-binding sites within the telomeric poly $\left(\mathrm{C}_{1}\right.$ $\left.{ }_{3} \mathrm{~A}\right)$ tracts. It remains to be seen whether telomeric silencing is also independent of RIFl. The reason for telomere elongation in both rap $1^{s}$ and rif1 mutants remains unclear and is puzzling in light of the observation that mutations in SIR2-SIR4, which abolish repression at silent mating-type loci and telomeres, have no effect on telomere length (D. Gottschling, pers. comm.). However, the correlation between the strength of rap $1^{s}$ silencing defects and the extent of telomere elongation (Sussel and Shore 1991) suggests that these two phenomena are related at some level. Perhaps mechanisms controling telomere length are more sensitive to the effects of rap $1^{\mathrm{s}}$ and rif1 mutations than is the telomeric silencing machinery.

\section{Other RIFs}

Given both the multiple functions of RAPl in silencing and the requirement for RIF1 in only one RAP1-mediated silencing pathway, it seems reasonable to assume that other RIFs contribute to silencing at wild-type and $h m r \Delta B$ silencers. We showed recently that overexpression of a $G_{\mathrm{BD}} / \mathrm{RAPl}$ hybrid partially derepresses $H M R$ wild-type and $h m r \Delta B$ silencers (Hardy et al. 1992). A disruption of the RIF1 gene, however, does not derepress either the wild-type or $h m r \Delta B$ silencers nor does it mitigate the partial derepression effect of a $\mathrm{G}_{\mathrm{BD}} / \mathrm{RAP1}$ hybrid on these silencers (data not shown). Because the 
$\mathrm{G}_{\mathrm{BD}} / \mathrm{RAP} 1$ hybrid can derepress in the absence of RIF1 activity, we propose that it may work on these silencers by titrating a different RIF. The existence of other RAP1interacting proteins involved in silencing is highlighted further by the observation that the $\mathrm{G}_{\mathrm{BD}} / \mathrm{rapl}^{\mathrm{s}}$ hybrids are all effective derepressors, including the $\mathrm{G}_{\mathrm{BI}} / \mathrm{rap} 1-12$ and $\mathrm{G}_{\mathrm{BD}} /$ rapl-13 hybrids, which fail to interact with $\mathrm{G}_{\mathrm{AD}} /$ RIF1 in the two-hybrid system. Although the simplest model would propose that RIF1 is the factor titrated by the overexpression of $\mathrm{G}_{\mathrm{BD}} / \mathrm{RAPl}$ hybrids, these results raise the possibility that a protein-protein interaction (as yet unidentified) may, at least in part, underlie this phenomenon. Consequently, we are continuing to screen the library from which RIF1 was isolated and independent libraries in which yeast sequences are joined to $G_{A D}$ through the two other possible reading frames in search of new RIFs. It will be interesting to compare the results of these screens with pseudoreversion (extragenic suppressor) studies of rap $1^{s}$ mutants, which are currently under way (L. Sussel and D. Shore, unpubl.).

In conclusion, using the two-hybrid system, we have identified a protein that interacts with RAPl and functions in both transcriptional silencing and telomere length regulation. These studies provide the first direct evidence that a silencing function of RAP1 is mediated by selective interactions with another protein. RIF1 is not the product of any previously identified trans-acting regulator of silencing. Further study of RIF1, identification of additional RIFs, and characterization of their molecular targets should provide new insights into the regulation of silencers and telomeres.

\section{Materials and methods}

Strains and DNAs

Growth and manipulation of yeast strains was done according to standard procedures (Sherman et al. 1983). All experiments involving the two-hybrid system were performed in strain GGY:171 (leu2-2,112 his3 $\Delta 200 \Delta$ gal4 $\Delta$ gal80 GAL1-lacZ). A library of partial Sau3A-digested yeast genomic sequences in the vector pGAD2 (Chien et al. 1991) was generously provided by P. Bartel and S. Fields. Plasmid DNAs were rescued from GGY: 171 by transformation into $\mathrm{CaCl}_{2}$-treated $E$. coli strain BAl (thr leuB6 thi thy A trpC1117 hisB str ${ }^{\mathrm{R}}$ ), selecting simultaneously for ampicillin resistance and leucine prototrophy. RIF1 gene disruptions were done in strain W303-1B (HML $\alpha$ MAT $\alpha$ HMRa ade2-1 can1-100 his3-11,-15 leu2-3,-112 trp1-1 ura3-1), derivatives of W303-1B containing hmr::TRP1 loci (Sussel and Shore 1991), and an isogenic MAT $\alpha /$ MATa diploid (W303). $\mathrm{G}_{\mathrm{BD}}$ / RAP1 carboxy-terminal hybrids have been described previously (Hardy et al. 1992). $\mathrm{G}_{\mathrm{BD}} / \mathrm{rapl}^{\mathrm{s}}$ hybrids were constructed by replacing a $B g / I I-X b a I$ fragment from the original $\mathrm{G}_{\mathrm{BD}} / \mathrm{RAP} 1$ /653827) clone with the corresponding fragment from the mutant alleles. The resulting $\mathrm{G}_{\mathrm{BD}} / \mathrm{rap}^{\mathrm{s}}$ hybrids differ from the original $\mathrm{G}_{\mathrm{BD}} / \mathrm{RAP1}(653-827)$ hybrid only in those amino acids affected in the rap $1^{s}$ mutants. Deletion derivatives of the original $\mathrm{G}_{\mathrm{AD}} /$ RIFl plasmid were constructed by placing either the $\operatorname{Bam}(\mathrm{P})-$ $B a m(D)$ or the $B a m(P)-X b a I$ fragment encoding RIF1 sequences (see Fig. 1) downstream of the BamHI site at the fusion junction in plasmid pGAD2 (Chien et al. 1991). The 3' end points of the inserts are at the unique $\mathrm{XbaI}$ site in pGAD2.

\section{Isolation of RIF1 using the two-hybrid system}

The yeast GAL1-lacZ reporter strain GGY:171, containing a plasmid expressing the $\mathrm{G}_{\mathrm{BD}} / \mathrm{RAP1}$ (653-827) hybrid, was transformed with a library of genomic DNA fragments in the pGAD2 expression vector (a generous gift of P. Bartell and S. Fields) using the high-efficiency method of Schiestl and Geitz (1989). Transformants $(\sim 1000$ per plate) were selected on SC-His-Leu medium at $30^{\circ} \mathrm{C}$. After $3-5$ days of growth, colonies (1- to 1.5 $\mathrm{mm}$ diam.) were replica-plated onto SC-His-Leu plates containing X-gal. After 1-5 days, blue colonies were identified, purified by restreaking on SC-His-Leu plates, and retested by replica plating onto X-gal plates. Positive colonies were picked from the SC-His-Leu plates and grown overnight in $10 \mathrm{ml}$ of SC-Leu liquid medium. DNA prepared from these cultures was transformed into the Leu ${ }^{-}$E. coli strain BAl, and $\mathrm{Amp}^{\mathrm{R}} \mathrm{Leu}^{+}$transformants were selected. Plasmid DNA was prepared from at least six independent BAl transformants and tested by transformation into the yeast reporter strain GGY:171 with or without the $\mathrm{G}_{\mathrm{BD}} / \mathrm{RAPl}(653-827)$-expressing plasmid. Yeast transformants were also assayed for lac $Z$ expression by replica-plating onto nitrocellulose (Breeden and Nasmyth 1985).

\section{Isolation of $a G_{A D} /$ rif1 mutant}

The original $\mathrm{G}_{\mathrm{AD}} / \mathrm{RIFl}$ plasmid was transformed into a mutD5 E. coli strain (Echols et al. 1983), selecting for ampicillin resistance on minimal M65 medium. Eight individual transformants were picked and grown to saturation in $10 \mathrm{ml}$ of LB media containing $20 \mu \mathrm{g} / \mathrm{ml}$ of ampicillin. DNA preparations from these eight cultures were pooled and used to transform yeast strain GGY:171 containing a plasmid expressing the $\mathrm{G}_{\mathrm{BD}} / \mathrm{rapl}$ 12 hybrid. Transformants were selected on SC-His-Leu plates. After 2-3 days of growth, replicas were made onto nitrocellulose filters and tested for $\beta$-galactosidase activity. One blue colony was detected from $\sim 15,000$ transformants. Plasmid DNA was rescued from the single blue transformant and tested as described above. The rescued plasmid was shown to confer the blue colony phenotype only upon retransformation of GGY:171 strains containing $\mathrm{G}_{\mathrm{BD}} / \mathrm{rapl}^{\mathrm{s}}$ or $\mathrm{G}_{\mathrm{BD}} / \mathrm{RAPl}$ hybrids. The mutation was localized to a small restriction fragment of the $\mathrm{G}_{\mathrm{AD}} /$ rif 1-1 plasmid by exchanging corresponding fragments with the original plasmid encoding the $\mathrm{G}_{\mathrm{AD}} / \mathrm{RIFI}$ hybrid. An XbaI-NcoI fragment from the mutagenized plasmid conferred the mutant phenotype when placed in the $\mathrm{G}_{\mathrm{AD}} / \mathrm{RIF} 1$ plasmid background. The sequence of the complete RIF1-coding sequence on this fragment was determined using synthetic oligonucleotide primers, and a single-base change was found at nucleotide 6169 $(\mathrm{G} \rightarrow \mathrm{A})$.

\section{Other methods}

Liquid assays for $\beta$-galactosidase were performed as described previously (Hardy et al. 1992). The average value from at least four transformants of each plasmid construct is reported. Values for individual colonies differed by $<30 \%$ from the average. Transcriptional silencing was assayed in strains containing hmr::TRP1 loci (with wild-type or mutated silencer elements) by measuring colony-forming ability on media lacking tryptophan (Sussel and Shore 1991). Telomere tract lengths were 
measured by Southern blot analysis of Xhol-digested genomic DNA using poly[d(G-T)] poly[d(C-A)] probes (Shampay and Blackburn 1988). DNA sequencing was done primarily on an Applied Biosystems 373A, using the universal primer and a series of nested deletion clones generated by exonuclease III digestion or using synthetic oligonucleotide primers corresponding to sequence generated from the deletions. The sequence reported has been determined on both strands. Details of primers and deletions used in the sequencing are available on request. We compared the RIFl sequence to sequences in data bases (SWISS-PROT 19.0, and GenPept 69.01 using the FASTA program (Pearson and Lipman 1988). In addition, Dr. M. Goebl compared the RIF 1 sequence to an independent data base and failed to find any significant similarities to other proteins $\mid M$. Goebl, pers. comm.

\section{Acknowledgments}

We thank Stan Fields and Paul Bartel for the very generous gift of the yeast genomic DNA-pGAD2 library and advice throughout the course of this work. We also thank Rolf Sternglanz and Chien-Ting Chien for considerable advice and encouragement; members of the Shore laboratory for helpful discussions; Ula Beauchamp for DNA sequencing; Aaron Mitchell, Stan Fields, and Susan Wente for comments on the manuscript; and Mark Goebl for sequence comparisons. This work was supported by grants from the National Institutes of Health (NIH) (CrM40094), the American Cancer Society (ACS! (JFRA-231 and MV-534), the Searle Scholars Fund/Chicago Community Trust, and the Irma T. Hirschl Charitable Trust to D.S., and by an ACS Institutional Research Grant [IRG-177A\} to the Comprehensive Cancer Center at Columbia University. C.H. was supported by a training grant from the NIH (T32 GM08281), and L.S. was a predoctoral trainee on a Cancer Biology Grant [CA09503-0] from the NIH.

The publication costs of this article were defrayed in part by payment of page charges. This article must therefore be hereby marked "advertisement" in accordance with 18 USC section 1734 solely to indicate this fact.

\section{References}

Andrews, B.J. and I. Herskowitz. 1990. Regulation of cell cycledependent gene expression in yeast. 1 . Biol. Chem. 265: 14057-14060.

Aparicio, O.M., B.L. Billington, and D.E. Gottschling. 1991. Modifiers of position effect are shared between telomeric and silent mating-type loci in S. cerevisiae. Cell 66: 12791287.

Axelrod, A. and J. Rine. 1991. A role for CDC7 in repression of transcription at the silent mating-type locus HMR in Saccharomyces cerevisiae. Mol. Cell. Biol. 11: 1080-1091.

Bauer, G.A. and P.M. Burgers. 1990. Molecular cloning, structure and expression of the yeast proliferating cell nuclear antigen gene. Nucleic Acids Res. 18: 261-265.

Brand, A.H., L. Breeden, J. Abraham, R. Sternglanz, and K. Nasmyth. 1985. Characterization of a "silencer" in yeast: A DNA sequence with properties opposite to those of a transcriptional enhancer. Cell 41: 41-48.

Brand, A.H., G. Micklem, and K. Nasmyth. 1987. A yeast silencer contains sequences that can promote autonomous plasmid replication and transcriptional activation. Cell 51: 709-719.

Breeden, L. and K. Nasmyth. 1985. Regulation of the yeast $H O$ gene. Cold Spring Harbor Symp. Quant. Biol. 50: 643-650.

Brill, S.J. and B. Stillman. 1991. Replication factor-A from Saccharomyces cerevisiae is encoded by three essential genes coordinately expressed at S phase. Genes \& Dev. 5: 15891600.

Buchman, A.R., W.J. Kimmerly, J. Rine, and R.D. Kornberg. 1988a. Two DNA-binding factors recognize specific sequences at silencers, upstream activating sequences, autonomously replicating sequences, and telomeres in Saccharomyces cerevisiae. Mol. Cell. Biol. 8: 210-225.

Buchman, A.R., N.F. Lue, and R.D. Kornberg. 1988b. Connections between transcriptional activators, silencers, and telomeres as revealed by functional analysis of a yeast DNA binding protein. Mol. Cell. Biol. 8: 5086-5099.

Chien, C.-T., P.L. Bartel, R. Sternglanz, and S. Fields. 1991. The two-hybrid system: A method to identify and clone genes for proteins that interact with a protein of interest. Proc. Natl. Acad. Sci. 88: 9578-9582.

Conrad, M.N., J.H. Wright, A.J. Wolf, and V.A. Zakian. 1990. RAPl protein interacts with yeast telomeres in vivo: Overproduction alters telomere structure and decreases chromosome stability. Cell 63: 739-750.

Diffley, J.F. and B. Stillman. 1988. Purification of a yeast protein that binds to origins of DNA replication and a transcriptional silencer. Proc. Nat1. Acad. Sci. 85: 2120-2124.

- 1989. Similarity between the transcriptional silencer binding proteins ABF1 and RAP1. Science 246: 1034-1038.

Dynlacht, B.D., T. Hoey, and R. Tjian. 1991. Isolation of coactivators associated with the TATA-binding protein that mediate transcriptional activation. Cell 66: 563-576.

Ebright, R.H., A. Kolb, H. Buc, T.A. Kunkel, J.S. Krakow, and J. Beckwith. 1987. Role of glutamic acid-181 in DNA-sequence recognition by the catabolite gene activator protein (CAP) of Escherichia coli: Altered DNA-sequence-recognition properties of Val181-CAP and Leu181-CAP. Proc. Natl. Acad. Sci. 84: 6083-6087.

Echols, H., C. Lu, and P.M.J. Burgers. 1983. Mutator strains of Escherichia coli, mutD and dnaQ, with defective exonucleotide editing by DNA polymerase III holoenzyme. Proc. Natl. Acad. Sci. 80: 2189-2192.

Fassler, J.S. and F. Winston. 1989. The Saccharomyces cerevisiae SPT13/GAL11 gene has both positive and negative regulatory roles in transcription. Mol. Cell. Biol. 9: 5602-5609.

Fields, S. and O.K. Song. 1989. A novel genetic system to detect protein-protein interactions. Nature 340: 245-246.

Flanagan, P.M., R.J. Kelleher, M.H. Sayre, H. Tschochner, and R.D. Kornberg. 1991. A mediator required for activation of RNA polymerase II transcription in vitro. Nature 350: 436438.

Francesconi, S.C. and S. Eisenberg. 1991. The multifunctional protein $\mathrm{OBF} 1$ is phosphorylated at serine and threonine residues in Saccharomyces cerevisiae. Proc. Natl. Acad. Sci. 88: 4089-4093.

Giesman, D., L. Best, and K. Tatchell. 1991. The role of RAPl in the regulation of the MAT $\alpha$ locus. Mol. Cell. Biol. 11: 10691079.

Gottschling, D.E., O.M. Aparicio, B.L. Billington, and V.A. Zakian. 1990. Position effect at $S$. cerevisiae telomeres: Reversible repression of pol II transcription. Cell 63: 751-762.

Guthrie, C. 1991. Messenger RNA splicing in yeast: Clues to why the spliceosome is a ribonucleoprotein. Science 253: $157-163$.

Haber, J.E. and J.P. George. 1979. A mutation that permits the expression of normally silent copies of mating type information in Saccharomyces cerevisiae. Genetics 93: 13-35.

Halfter, H., B. Kavety, J. Vandekerckhove, F. Kiefer, and D. Gall- 
witz. 1989. Sequence, expression and mutational analysis of BAF1, a transcriptional activator and $A R S 1$-binding protein of the yeast Saccharomyces cerevisiae. EMBO J. 8: 42654272.

Hardy, C.F.J. 1991. "Studies on RAP1 and the RAP1 interacting factor, RIF1." Ph.D. thesis, Columbia University, New York.

Hardy, C.F.J., D. Balderes, and D. Shore. 1992. Dissection of a carboxy-terminal region of the yeast regulatory protein RAPl with effects on both transcriptional activation and silencing. Mol. Cell. Biol. 12: 1209-1217.

Kayne, P.S., U.J. Kim, M. Han, J.R. Mullen, F. Yoshizaki, and M. Grunstein. 1988. Extremely conserved histone H4 N terminus is dispensable for growth but essential for repressing the silent mating loci in yeast. Cell 55: 27-39.

Keleher, C.A., C. Goute, and A.D. Johnson. 1988. The yeast cell-type-specific repressor $\alpha 2$ acts cooperatively with a noncell-type-specific protein. Cell 53: 927-936.

Keleher, C.A., S. Passmore, and A.D. Johnson. 1989. Yeast repressor $\alpha 2$ binds to its operator cooperatively with yeast protein Mcml. Mol. Cell. Biol. 9: 5228-5230.

Kimmerly, W., A. Buchman, R. Kornberg, and J. Rine. 1988. Roles of two DNA-binding factors in replication, segregation and transcriptional repression mediated by a yeast silencer. EMBO I. 7: 2241-2253.

Klar, A.J.S., S. Fogel, and K. McLcod. 1979. MAR1-A regulator of HMa and $H M \alpha$ loci in Saccharomyces cerevisiae. Genetics 93: 37-50.

Klar, A.J.S., S.N. Kakar, I.M. Ivy, J.B. Hicks, G.P. Livi, and L.M. Miglio. 1985. SUM1, an apparent positive regulator of cryptic mating-type loci in Saccharomyces cerevisiae. Genetics 111: 745-758.

Kurtz, S. and D. Shore. 1991. The RAP1 protcin activates and silences transcription of mating-type genes in yeast. Genes \& Dev. 5: 616-628.

Laurenson, P. and J. Rinc. 1991. SUM1-1: A suppressor of silencing defects in Saccharomyces cerevisiae. Genetics 129: 685-696.

Livi, G.P., J.B. Hicks, and A.J.S. Klar. 1990. The sum1-1 mutation affects silent mating-type gene transcription in Saccharomyces cerevisiae. Mol. Cell. Biol. 10: 409-412.

Longtine, M.S., N.M. Wilson, M.E. Petracek, and J. Berman. 1989. A yeast telomere binding activity binds to two related telomere sequence motifs and is indistinguishable from RAP1. Curr. Genet. 16: 225-240.

Lowndes, N.F., A.L. Johnson, and L.H. Johnston. 1991. Coordination of expression of DNA synthesis genes in budding yeast by a cell-cycle regulated trans factor. Nature 350: $247-$ 250.

Lustig, A.J., S. Kurtz, and D. Shore. 1990. Involvement of the silencer and UAS binding protein RAP1 in regulation of telomere length. Science 250: 549-553.

Mahoney, D.J., R. Marquardt, G.-J. Shei, A.B. Rose, and J.R. Broach. 1991. Mutations in the HML E silencer of Saccharomyces cerevisiae yield metastable inheritance of transcriptional repression. Genes \& Dev. 5: 605-615.

Megee, P.C., B.A. Morgan, B.A. Mittman, and M.M. Smith. 1990. Genetic analysis of histone H4: Essential role of lysines subject to reversible acetylation. Science 247: 841845.

Miller, A.M. and K.A. Nasmyth. 1984. Role of DNA replication in the repression of silent mating-type loci in yeast. Nature 312: $247-251$.

Miller, A.M., R. Sternglanz, and K.A. Nasmyth. 1984. The role of DNA replication in the repression of the yeast matingtype silent loci. Cold Spring Harbor Symp. Quant. Biol. 49: $105-113$.
Mullen, J.R., P.S. Kayne, R.P. Moerschell, S. Tsunasawa, M. Gribskov, S.M. Colavito, M. Grunstein, F. Sherman, and R. Sternglanz. 1989. Identification and characterization of genes and mutants for an $\mathrm{N}$-terminal acetyltransferase from yeast. EMBO I. 8: 2067-2075.

Nasmyth, K.A. 1982. The regulation of yeast mating-type chromosome structure by SIR: An action at a distance affecting both transcription and transposition. Cell 30: 567-578.

Nishizawa, M., Y. Suzuki, Y. Nogi, K. Matsumoto, and T. Fukasawa. 1990. Yeast Gall1 protein mediates the transcriptional activation signal of two different transacting factors, Gal4 and general regulatory factor I/repressor/activator site binding protein 1/translation upstream factor. Proc. Natl. Acad. Sci. 87: 5373-5377.

Pearson, W.R. and D.J. Lipman. 1988. Improved tools for biological sequence comparison. Proc. Natl. Acad. Sci. 85: 2444-2448.

Pillus, L. and J. Rine. 1989. Epigenetic inheritance of transcriptional states in $S$. cerevisiae. Cell 59: 637-647.

Pizzagalli, A., P. Valsasnini, P. Plevani, and G. Lucchini. 1988. DNA polymerase I gene of Saccharomyces cerevisiae: Nucleotide sequence, mapping of a temperature-sensitive mutation, and protein homology with other DNA polymerases. Proc. Natl. Acad. Sci. 85: 3772-3776.

Rhode, P.R., K.S. Sweder, K.F. Oegema, and J.L. Campbell. 1989. The gene encoding ARS-binding factor I is essential for viability of yeast. Genes \& Dev. 3: 1926-1939.

Rine, J. and I. Herskowitz. 1987. Four genes responsible for a position effect on expression from $H M L$ and $H M R$ in Saccharomyces cerevisiae. Genetics 116: 9-22.

Rotenberg, M.O. and J.L.J. Woolford. 1986. Tripartite upstream promoter element essential for expression of Saccharomyces cerevisiae ribosomal protein genes. Mol. Cell. Biol. 6: 674687.

Santangelo, G.M. and J. Tornow. 1990. Efficient transcription of the glycolytic gene $A D H 1$ and three translational component genes requires the GCR1 product, which can act through TUF/GRF/RAP binding sites. Mol. Cell. Biol. 10: $859-862$.

Schiestl, R.H. and R.D. Gietz. 1989. High efficiency transformation of intact yeast cells using single stranded nucleic acids as a carrier. Curr. Genet. 16: 339-346.

Shampay, J. and E.H. Blackburn. 1988. Generation of telomerelength heterogeneity in Saccharomyces cerevisiae. Proc. Natl. Acad. Sci. 85: 534-538.

Shampay, J., J.W. Szostak, and E.H. Blackburn. 1984. DNA sequences of telomeres maintained in yeast. Nature 310: 154 157.

Sherman, F., G.R. Fink, and J.B. Hicks. 1983. Methods in yeast genetics. Cold Spring Harbor Laboratory, Cold Spring Harbor, New York.

Shore, D. and K. Nasmyth. 1987. Purification and cloning of a DNA binding protein from yeast that binds to both silencer and activator elements. Cell 51: 721-732.

Shore, D., D.J. Stillman, A.H. Brand, and K.A. Nasmyth. 1987. Identification of silencer binding proteins from yeast: Possible roles in SIR control and DNA replication. EMBO $\%$ 6: 461-467.

Stanway, C.A., A. Chambers, A.J. Kingsman, and S.M. Kingsman. 1989. Characterization of the transcriptional potency of sub-elements of the UAS of the yeast $P G K$ gene in a $P G K$ mini-promoter. Nucleic Acids Res. 17: 9205-9218.

Stone, E.M., M.J. Swanson, A.M. Romeo, J.B. Hicks, and R. Sternglanz. 1991. The SIR1 gene of Saccharomyces cerevisiae and its role as an extragenic suppressor of several mating-defective mutants. Mol. Cell. Biol. 11: 2253-2262. 
Hardy et al.

Sussel, L. and D. Shore. 1991. Separation of transcriptional activation and silencing functions of the RAP1-encoded repressor/activator protein 1: Isolation of viable mutants affecting both silencing and telomere length. Proc. Natl. Acad. Sci. 88: 7749-7753.

Walmsley, R.M., C.S. Chan, B.-K. Tye, and T.D. Petes. 1984 Unusual DNA sequences associated with the ends of yeast chromosomes. Nature 310: 157-160.

Whiteway, M., R. Freeman, S. Van Arsdell, J.W. Szostak, and J. Thorner. 1987. The yeast $A R D 1$ gene product is required for repression of cryptic mating-type information at the $H M L$ locus. Mol. Cell. Biol. 7: 3713-3722. 


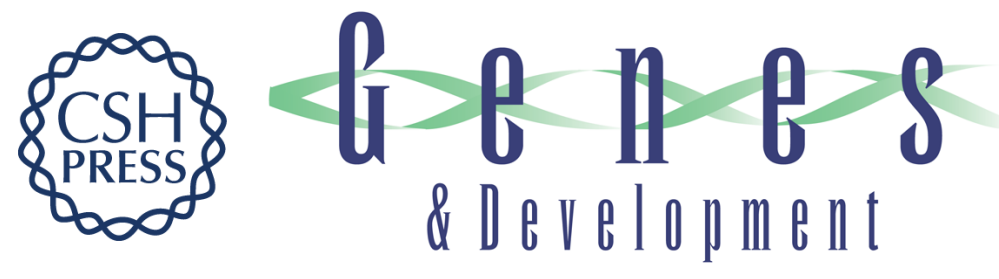

\section{A RAP1-interacting protein involved in transcriptional silencing and telomere length regulation.}

C F Hardy, L Sussel and D Shore

Genes Dev. 1992, 6:

Access the most recent version at doi:10.1101/gad.6.5.801

References This article cites 63 articles, 37 of which can be accessed free at:

http://genesdev.cshlp.org/content/6/5/801.full.html\#ref-list-1

License

Email Alerting

Service

Receive free email alerts when new articles cite this article - sign up in the box at the top right corner of the article or click here.

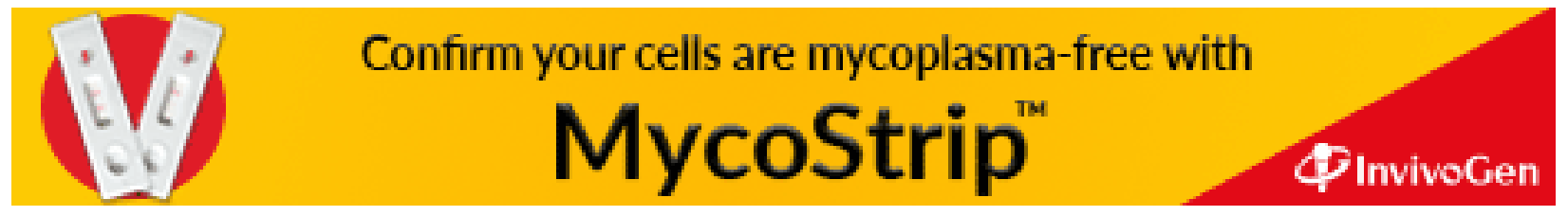

